\title{
Financing decisions along a firm's life-cycle: debt as a commitment device
}

\author{
Julia Hirsch ${ }^{\text {a* }}$ \\ Iberoamerican University Mexico City \\ Uwe Walz ${ }^{\mathrm{b} *}$ \\ Goethe University Frankfurt, CFS Frankfurt and ZEW Mannheim
}

October 2009

\begin{abstract}
We analyze the life-cycle patterns of a firm's financing decisions and their interaction with future growth and development decisions. The framework derives three different financing sequences (debt-debt, equity-debt, equity-equity financing) which we link to existing empirical research. Furthermore, by adopting a life-cycle approach we are able to go one step beyond existing empirical research and derive testable hypotheses with respect to differences in the financing decisions of firms due to project, firm, market and country characteristics as well as the impact of a possible lack of start-up financing possibilities on firm dynamics.
\end{abstract}

Keywords: financing decisions, life-cycle, firm growth, path-dependencies JEL classification: D92, G32

\footnotetext{
${ }^{a}$ Address: Iberoamerican University Mexico City, Prolongación Paseo de la Reforma 880, Mexico City 01219, Mexico Tel: +52 5559504000 Ext. 7351. Email: julia.hirsch@uia.mx.

${ }^{\mathrm{b}}$ Goethe University Frankfurt, Postfach 54, Grüneburgplatz 1, 60629 Frankfurt, Germany. Tel: +49 (0) 69 79834807. Email: uwalz@econ.uni-frankfurt.de

*Financial support by the German Research Foundation (DFG) is gratefully acknowledged.
} 


\section{Introduction}

Entrepreneurial finance and corporate finance are often considered to be separate fields dealing with different types of firms. Albeit much of the knowledge about entrepreneurial firms comes from empirical evidence on already established firms. Furthermore, in both fields, the pecking-order theory and the trade-off theory are used as the main candidates for explaining the financing decisions of firms. In a recent paper, however, Robb and Robinson [2009] using data on very young firms show that these two main theories do not explain the data well. They reveal that, contrary to many accounts of start-up activity, firms rely heavily on external debt sources such as bank financing and less extensively on the financial resources of friends and family. Further empirical research suggests that the observable capital structure of firms varies with the age of the firm and their stage of development. Starting with Berger and Udell [1998] a number of studies illustrate the importance of controlling for a firm's life-cycle stage (see e.g. Cole [2008] and Bulan and Yan [2009]). These studies acknowledge that financing choices evolve over time with the firm's changing characteristics but also stress the importance of the initial conditions and prior financing decisions. Nevertheless, the huge literature on capital structure theory does not take the life-cycle aspect into account. The main body of literature deals with static approaches (see e.g. Tirole [2006]) for an extensive overview), with dynamic agency problems associated with a single financing decision (see e.g. Anderson and Nyborg [2001]) or with dynamic convergence towards an optimal unique debt-equity ratio (see e.g. Clementi and Hopenhayn [2006], Dangl and Zechner [2006] and Hennessy and Whited [2005]) while leaving life-cycle issues aside. ${ }^{1}$

Our paper tries to narrow this gap by investigating the life-cycle patterns of a firm's financing decisions as well as their interaction with its future strategic decisions about growth and development. Thereby, we aim to provide a link between entrepreneurial and corporate finance. To be more precise, our main research questions are the following: What are the drivers of different financing sequences across a firm's life-cycle and how do they relate to the firm's development path? How may potential path dependencies, e.g. initial debt financing, come about and how do they affect future financing in the expansion phase as well as the firm's expansion strategy? How do institutional restrictions in some countries, e.g. the limited access to public equity, impact the firm's development path as well as its remaining financing decisions?

Our model set-up is rich enough to allow for three different financing sequences de-

\footnotetext{
${ }^{1}$ Exceptions to the neglect of the life-cycle issue are recent papers by Fluck [2000], Titman and Tsyplakov [2006] as well as Sarkar [2007] who also consider path dependencies resulting from initial financing choices. But while these paper allow for a sequence of financing decisions leading to varying optimal capital structures over the firm's life time, they are silent on the consequences of this choices on the firms's future strategic expansion decisions.
} 
pending on project, firm as well as market characteristics: debt financing at both the development and the expansion stages, equity financing at both stages or equity financing at the development stage with subsequent debt financing at the expansion stage. Thus, it is able to provide an explanation for some of the patterns observed by recent empirical studies on financing decisions in and across different stages of a firm's life-cycle. Our model predicts debt financing at both stages for firms which are realizing rather capital-intensive projects or projects which require less specific investments. In this case, start-up debt financing may serve as a commitment device to discontinue non-profitable excessively risky projects. This case is in line with the evidence of Robb and Robinson [2009] about the high importance of start-up debt financing. Equity-debt financing as observed in the study by Byoun [2008] should rather be observed for widely held firms or in countries where the entrepreneur suffers little from stigmatization costs due to failure in combination with rather capital-intensive projects. On the contrary, for closely-held firms or firms in countries where the entrepreneur suffers strongly from stigmatization costs due to failure, in combination with human-capital intensive projects, we predict equity financing at both development stages. Both financing sequences are in line with Dang [2008] and Aghion et al. [2004] who show that better growth opportunities and higher R\&D investments are more probable to be financed via equity.

Though, our model goes one step beyond the existing empirical evidence underlining the strong interaction which exists between the financing decision taken at the start-up stage and the subsequent financing as well as investment decisions. Indeed, we are able to show that both equity as well as debt financing at the start-up stage take a crucial role for the future development of firms. This is due to the fact that debt financing can be used as a commitment device in order to discontinue too risky, non-profitable projects. In contrast, equity financing at the start-up stage opens the possibility of debt financing at the expansion stage without its restrictive consequences and thus induces efficient continuation decisions. Furthermore, this approach of the interaction of financing and investment decisions is particularly interesting as it highlights the impact of a lack of start-up equity or debt financing respectively. Indeed, our model predicts that the lack of both financing sources - depending on the specific project, firm as well as market characteristics - may induce a slowdown in the firm dynamics.

In order to derive these results, we propose a dynamic model in which entrepreneurs face a dynamic financing problem. They have to decide upon the financing of their firm in the start-up as well as in the expansion phase. After the financing choice of the expansion stage, the precise nature of the development path of the firm is determined. The entrepreneur has to decide whether a risky project path with high growth potentials or a more secure, but less promising development path will be chosen. Risky projects are 
liquidated if the cash-flows are not sufficient to satisfy external investors. Financing as well as project choice decisions take place against the background of a trade-off between the costs of equity and debt. In order to depict the specific nature of the life-cycle of the firms and the associated different stages of development, we allow for costs of debt and equity which differ among stages. The interplay of the relative disadvantages of both types of external financing determines the choice of financing in our two-stage model. The costs of debt consist of a commitment effect which is due to the fact that the debtor in the start-up phase requires more tangibles. Hence, the debtor forces entrepreneurs to reduce the risk profile of the firm. In addition, in both stages, we consider a classical risk-shifting effect. Since financing the firm with debt leaves the entrepreneur with a more convex payoff scheme, the incentives for risk taking are increased. Hence, the entrepreneur may be inclined to choose too often the risky project. There is, however, a potential flip-side of this effect in our model. As debt financing allows, in contrast to equity financing, the termination of projects in bad states, debt may induce in case of firms with very high leverage over-liquidation of projects: our risk-avoidance effect of debt. The costs of equity arise from an overvaluation effect and from the fact that, in contrast to debt, minority shareholders fail to have rights to liquidate the project. The overvaluation effect, caused by initial equity financing, describes the distortion of the entrepreneur's relative weight of monetary and non-monetary payoffs increasing the incentives to continue projects too often.

Our model is related to three strands of the literature. First, our analysis has to be seen and contrasted with research which looks into empirical capital structure patterns against the background of the pecking-order and trade-off theory. Second, we build on models which analyze the costs and benefits of debt and equity financing and their impact on the firm's investment decisions in one-period models. Third, there exists a large literature which highlights the relation which exists between subsequent financing decisions and firm growth.

As concerns empirical evidence, we have to note that the majority of papers confronts the pecking order theory with the trade-off theory when analyzing the capital structure of small and medium-sized enterprises (SMEs). Cole [2008], for example, analyzes the capital structure decisions of privately held companies in the United States and shows that leverage is negatively related to firm size, age, profitability, liquidity and credit quality, and positively to firm tangibility and limited liability. Thus, his results seem to speak more in favor of the pecking-order theory than the trade-off theory. This result is confirmed by a large number of studies about the capital structure of small and medium-sized firms (see, for example, the evidence of Chittenden et al. [1996] for SMEs in the UK, Cassar [2004] for SMEs in Australia, Sogorb Mira [2002] for SMEs in Spain, Bhaird and Lucey 
[2006] for firms in Ireland or Klapper et al. [2006] for firms in Poland). However, it is not clear whether these results hold independently of the type of firm. Frank and Goyal [2003], for example, show that - contrary to the theory's predictions - the pecking order theory seems to work only well for large firms. Though, it is important to underline that none of the mentioned studies analyzes the evolution of the firm's capital structure across time. When analyzing data of firms at different stages of their life-cycle, Bulan and Yan [2009] show that the impact of certain classic determinants like, for example, profitability is not monotonic across different stages of the firm's life-cycle. This underlines the importance to control for the development stage when making capital structure analysis. Nevertheless, they are able to find supportive evidence for the pecking order theory for each of the two stages they analyze.

The only empirical paper which analyzes to the best of our knowledge, the evolution of the firm's capital structure is Byoun [2008]. He shows that the evolution of the firm's capital structure is rather explained by financial flexibility concerns than by the pecking order theory. He shows that developing firms use rather equity financing to maintain financial flexibility, growth firms have high leverage ratios and mature firms rather use internal financing.

As concerns the second strand of literature, by modelling the role of debt and equity as well as the relation between financing and investment decisions, we borrow from existing mechanisms in the literature. Grossman and Hart [1982], for example, show that an entrepreneur may prefer debt to equity financing in order to credibly commit to pursue profits instead of perquisites afterwards. In the same spirit, Liu [2006] stresses that outside financing may help to solve time inconsistency problems with respect to the entrepreneur's liquidation decisions. In addition, there exist some recent papers that underline the strong relation that exists between financing and investment decisions. Chakraborty [2009], for example, shows that in an asymmetric information framework about the firm's quality, it may be possible that debtholders limit the investment and thus the growth opportunities of the firm. Therefore, growth opportunities should rather be equity-financed. Analogously, the model of Barclay et al. [2006] predicts a negative relation between book leverage and growth opportunities. Though, in this last paper, the result is driven by a trade-off between underinvestment costs and cash-flow benefits associated with additional debt financing. Anderson and Nyborg [2001] partially confirm these results in a two-stage model of firm growth with a cash-diversion problem. However, contrary to the first two papers, they show that while debt financing may reduce second-stage growth it induces first-stage growth. Equity financing, on the contrary, induces second-stage growth at the expense of first-stage growth. Finally, the paper of Boyer et al. [2005] combines to a certain degree both of the mentioned aspects by pointing out the impact of financing 
decisions on technological choice and the role of debt as a commitment device to a specific technology afterwards. Finally, the idea of our framework about the ambiguity of debt financing producing both risk-avoidance as well as risk-shifting is based on Almeida Brito and John [2002] who, however, rely on a static model only.

Third, the idea of a relationship between financing decisions at different stages of the firm's development is not new. Indeed, there exists a vast literature on dynamic capital structure choices (see, for example, Mauer and Triantis [1994], Hennessy and Whited [2005], Titman and Tsyplakov [2006] or Strebulaev [2006]) which mainly focuses on the dynamic adjustment process of leverage across time. The early paper of Mauer and Triantis [1994] analyzes the impact of production and financial flexibility on the interactions between the firm's investment and financing decisions. Hennessy and Whited [2005] show the determinants of the current amount and type of financing of a firm anticipating future financing needs under uncertainty. However, in the majority of these papers, the target leverage ratio is fixed and thus, the position of the firm in its development process is not important. Only recent papers have tried to allow changes in the target debt ratios and analyze the determinants of these changes over time (see, for example, Titman and Tsyplakov [2006]). Though, even in these models, the main focus still lies on the adjustment processes rather than on the impact of the initial financing structure on the future financing and investment decisions of the firm. Moreover, the types of decisions which are taken are qualitatively the same at every stage and strategic expansion decisions of the firm are not central.

The paper whose idea is most closely related to the present framework is the model of Sarkar [2007]. He models the firm's financing decision at the expansion stage in a real option model taking into account the pre-expansion capital structure decisions. His approach is different from the aforementioned papers as he models the interactions between financing and investment decisions due to over- and underinvestment problems associated with debt financing. Notwithstanding, differently to our model, in his model, the time of exercise of the growth opportunities drives the results due to the risk of bankruptcy.

The paper is organized as follows. In the next section, we outline the basic model. Section 3 discusses the (dis)continuation decision against the background of different financing sequences. In section 4 , we investigate the project choice of the entrepreneur given certain financing sequences. Section 5 deals with the financing choices at the expansion stage. Section 6 looks into the determinants of the financing choices in the firm's initial start-up phase. In section 7, we address the implications of the lack of financing possibilities due to institutional constraints. The main implications of our analysis are discussed in section 8 where we also provide a number of testable hypotheses emerging from our analysis. The last section concludes. 


\section{The model}

\subsection{The basic framework}

We develop a model which addresses the dynamic financing choice of an entrepreneur in the start-up as well as in the subsequent expansion stage. Thereby, the financing choices are interrelated with the entrepreneur's choice of investment projects. The focus of our model lies in potential dynamic aspects of initial financing choices in the start-up period, i.e. the long-run implications of initial financing choices on expansion stage financing as well as on project choices at later stages of the firm's development.

The firm's project can be either financed with debt or equity. Investments take place in two tranches: $I_{1}$ at the start-up phase and $I_{2}$ at the expansion stage. Due to the fact that $I_{2}$ is initially unknown financing will take place in two steps as well. To carve out the main mechanisms at hand as clearly as possible, we assume that there is no learning between the two financing stages (except learning $I_{2}$ ). In addition, there is no asymmetric information between the investors and the entrepreneur: both are incompletely informed with respect to the quality of the risky project to the same extent in both financing stages.

\section{$2.2 \quad$ Projects}

There are three projects: two risky ones and one with secure cash-flows. One of the risky projects comes at very high risk. Hence, we refer to it as H-project (high risk). The second project's risk profile is lower, implying less risk but higher expected cash-flows (project L). The third project, the safe one is referred to as project S. For each of the risky projects there are two potential realizations: with probability $1-\tau_{j}(j=H, L, S)$ the project is successful and the firm realizes cash-flows at the end of the start-up phase $(H)$ as well as expected profits $G^{j}$ over the firm's life time. We refer to these expected cash-flows as growth options. To reflect the main properties of our projects, we assume $\left(1-\tau_{H}\right)<\left(1-\tau_{L}\right)<\left(1-\tau_{S}\right)=1$ as well as $G^{H}>G^{L}>G^{S}$. If the risky projects are not successful in the start-up phase (this B-state occurs case with probability $\tau_{j}$ ) this does not imply that the projects are unsuccessful altogether. There still exists a growth option $\left(G_{B}^{L}\right.$ and $G_{B}^{H}$, respectively) which, however, pays out lower expected cash-flows than the growth options in the good state. Moreover, in the B-state, there are no cash-flows at the end of the start-up phase in case of continuation of the project. Consequently, it might be worthwhile for the entrepreneur or the investor to consider to discontinue the project in this state. If the project is discontinued a liquidation value accrues in both projects $\left(L^{H}\right.$ and $L^{L}$, with $L^{H}<L^{L}$ ). However, liquidation also implies that the entrepreneur foregoes his continuation payoff $F$. The order of total monetary expected profits of projects are as follows: $E \pi^{L}>E \pi^{S}>E \pi^{H}$ with $E \pi^{j}=\left(1-\tau_{j}\right)\left(H+G^{j}\right)+\tau_{j}\left(G_{B}^{j}\right)-I_{1}-I_{2}$ and $I_{1}$ and $I_{2}$ 
reflecting investment outlays in the start-up and expansion stages, respectively. That is, whereas the L-project is the most profitable project, the H-project is the least profitable one leading potentially even to negative expected profits. The safe project is in-between these two risky projects.

After having completed the explorative phase, resulting in a new technology or new products, the entrepreneur has to choose whether to stay on the innovative path (i.e. developing indeed a new product and marketing this product aggressively) or to switch to a more secure path. While the innovative path leads eventually to faster growth or failure, the secure path is, for matters of simplicity, assumed to be completely without risk. We model the financing and project choice decisions against the background of incomplete but symmetric information with respect to the quality of the project. That is, when deciding whether to stick to the risky project or revert to the safe project in the expansion phase, the entrepreneur does not fully know the quality of his project. The expected quality of the project is depicted by $q$ which reflects the probability that the H-project will emerge. With probability (1-q) the L-project will result if the entrepreneur decides to stick with the risky project. This reflects the overall notion that the entrepreneur starts and finances a risky venture. Moreover, the parameter $q$ can be interpreted as a measure of contractibility which may differ between industries and project types. The easier predictable and contractible the future development is, the lower should be $q$.

\section{$2.3 \quad$ Financing}

In both stages, the entrepreneur can choose between a standard debt contract and an equity contract. With the standard debt contract, the entrepreneur finances the respective investment outlays $I_{i}(i=1,2)$. In return, he faces the obligation to repay the debt at the expiration date of the debt contract (i.e. in $t=5$ ). We refer to these debt obligations as $D_{1}$ and $D_{2}$. With an equity contract, the investment outlays are financed via the issue of shares. In return, investors receive a proportion of the total cash-flows of the firm ( $\alpha_{1}$ and $\alpha_{2}$ or $\left(1-\alpha_{1}\right) \alpha_{2}$ in stage 2 with equity financing in both stages respectively). Whereas creditors do have only access to parts of the growth options in the B-state $\left(G_{B K}^{j}\right)$, shareholders get their respective shares of the full cash-flows originated by the growth options as well (see section 2.4 for details). Furthermore, none of the investors can benefit from the non-monetary continuation payoff $(F)$ of the entrepreneur. In addition, we assume that creditors in the first stage are only willing to finance the project if the firm commits itself to a lower risk profile reducing the value of the growth option in the B-state. This reflects the notion that debt financing in the first stage requires projects with more tangible assets and less upside potential. For simplicity, we assume that only the growth option of the L-project is reduced to $G_{B}^{L}(D)<G_{B}^{L}$. 
Whereas with debt contracts the firm is obliged to repay the face value of debt at the end of the respective period, equity contracts have no definite endpoint. Hence, while creditors can force the firm into bankruptcy and thus to discontinue the project, shareholders do not have such a right as long as they do not have a majority of voting rights or a put option, which we assume to be the case throughout the subsequent analysis.

\subsection{Contractibility}

We assume that only parts of the growth options in the B-state $\left(G_{B K}^{L}\right.$ and $\left.G_{B K}^{H}\right)$ are contractible. This reflects the notion that the growth options are a short-cut of a stochastic process which may lead to (very) high cash-flows throughout the life time of the firm while it may also lead to low or even zero output in the opposite case. Since the cashflows accrue over the firm's life, potentially long after the expansion phase has ended, it is difficult to contract on them for claims which call for repayment at the end of the expansion phase. Hence, the partial contractibility of the growth option delineates the fact that debtholders hold a claim which expires at the end of this period. In contrast, the shareholders' claims are indefinite giving them the opportunity to participate in the growth options proportionally to their claims in the firm. Theoretically, it would be feasible to allow for debt-equity conversion at the end of the expansion phase. We assume, however, that debtholders are, due to their higher time preference not willing to engage in such a conversion. In addition, given that the cash-flows in the good state $(H)$ suffice to cover the claims of the creditors, the degree of contractibility of the growth option for debtholders is not an issue in this case. Finally, in order to separate debt and equity claims as clearly as possible, we do not allow for liquidation rights (such as put options) for shareholders.

\subsection{Sequence of Decisions}

The sequence of decisions is as follows. In the first step, the entrepreneur decides on the mode of financing in the start-up phase. This decisions takes place given a common belief of the entrepreneur and the investors about the quality of the risky project $(q)$. In a second step, the entrepreneur decides at the beginning of the expansion stage on the second source of financing to acquire cash for the second investment period. At the time of this second financing round, the entrepreneur cannot commit himself whether he will stick to the risky expansion path or turning to the safe project, depicting here as a shortcut a less risky expansion path. This project decision is undertaken in $t=3$ by the entrepreneur who still shares the belief about the quality of the risky project $q$ with the investors. After the project choice, in the case of the choice of the risky project, the state of nature as well as the project type are revealed to all parties $(t=4)$. That is, investors as well as the entrepreneur can, when having opted for the risky project, observe whether 
the firm is a $\mathrm{H}$ or a L-project and whether the B-state or the good state has emerged. Given this information, the entrepreneur or the creditors can decide to discontinue the project in $t=5$ of the game after the realization of a cash-flow $H$ in the good state of the projects. If the project is continued, the expected cash-flows related to the growth options $G_{i}^{j}$ can be anticipated at the end (in $t=6$ ).

Figure 1: Time line

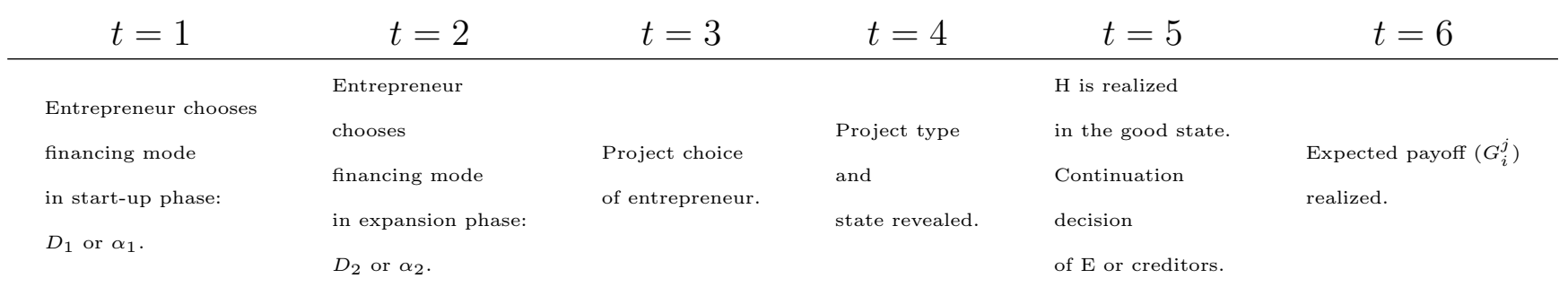

We solve in the following for the subgame perfect solution of our model.

\section{Continuation decisions at the expansion stage}

Before determining the continuation decisions taken by the entrepreneur and/or the creditors, we will analyze the first-best efficient continuation decisions and state a couple of assumptions which allow us to carve out our main mechanisms as clearly as possible. Given our set-up, it is always worthwhile to continue both projects in the good state $\left(H>D_{1}+D_{2}\right)$ while in the B-state, the two projects differ with respect to their optimal (first-best) continuation decision. We assume that it is never optimal to discontinue the L-project in the B-state, i.e. even the lowest continuation payoff $\left(G_{B}^{L}(D)+F\right)$ is always larger than the liquidation value $L^{L}$ :

$$
G_{B}^{L}(D)+F>L^{L}
$$

In contrast, it is optimal to discontinue the H-project in the B-state:

$$
G_{B}^{H}+F<L^{H}
$$

As concerns the actual continuation decisions, we have to take account of the fact that shareholders cannot force the firm to repay a certain amount of cash at a given moment in time. Hence, they cannot enforce the liquidation of neither project. With debt financing, on the contrary, a payment is due at $t=5$. We assume that the face value 
resulting from debt financing at the start-up stage only, is low enough such that the creditors can cover their repayment value in the B-state with the expected value of the contractible part of the growth option, i.e. $D_{1}<G_{B K}^{H}<G_{B K}^{L}(D)$. Although debtholders can threaten to discontinue the project at $t=5$ in the B-state, the entrepreneur is able to renegotiate the debt claim. We give, for matters of simplicity all bargaining power to the entrepreneur. Thus, he can increase the face value of the debt claim such that the expected value continues to be just $D_{1}$.

Hence, first-period debt is risk-free and will not be used to enforce the liquidation of the projects. Therefore, with debt-equity financing, investors will not enforce liquidation of neither project. Thus, in this case, the continuation decision hinges on the entrepreneur. He will continue the L-project if the sum of the expected monetary and non-monetary payoffs with continuation is higher than with liquidation. With debt financing in the first period (and equity in the second) this difference amounts to:

$$
\left(1-\alpha_{2}\right)\left(G_{B}^{L}(D)-D_{1}\right)+F-\left(1-\alpha_{2}\right)\left(L^{L}-D_{1}\right)=\left(1-\alpha_{2}\right)\left(G_{B}^{L}(D)-L^{L}+F\right)
$$

Given our first-best assumption, this difference is always positive for the L-project, hence leading to continuation of the L-project. For the H-project the entrepreneur will continue the project if

$$
G_{B}^{H}+F /\left(1-\alpha_{2}\right)>L^{H}
$$

which we assume to be the case.

As concerns pure equity financing, we know that the continuation decision also depends on the entrepreneur as shareholders are not able to force liquidation in the framework of our model. However, given the previous assumptions, the entrepreneur will neither discontinue any project in case of equity financing in both stages. This is due to the fact that he has even more incentives to continue the projects in the case of pure equity financing since the non-monetary returns play a relatively more pronounced role $(F /(1-$ $\left.\left.\alpha_{1}\right)\left(1-\alpha_{2}\right)\right)$.

On the contrary, the creditors can and will potentially enforce liquidation with debt financing in the second period. In order to stress both sides of debt, namely the potential to break-up projects efficiently as well as excessively, we consider the following two cases. First, we assume that debt financing in both stages leads to the liquidation of both projects. This is the case if

$$
D_{1}+D_{2}>L^{j}>G_{B K}^{j}(D)
$$

holds for both projects. Note that for the H-project $G_{B K}^{H}(D)=G_{B K}^{H}$ whereas for the L-project $G_{B K}^{L}(D)<G_{B K}^{L}$. 
In contrast, with equity financing in the first and debt financing in the second stage, we assume that this financing sequence leads to efficient continuation decisions. This also means that start-up equity financing should be the preferable choice in our model and we ask whether given this positive role, there is still room for debt financing in the first stage to be superior to equity financing. In order to guarantee efficient continuation decisions after equity-debt financing, the entrepreneur must be able to compensate the debtholder in case of renegotiations in the B-state of the L-project $\left(D_{2}<G_{B K}^{L}\right.$ must hold) and, additionally, he must himself have an incentive to avoid liquidation, i.e.

$$
\left(1-\alpha_{1}\right)\left(G_{B}^{L}-D_{2}\right)+F-\left(1-\alpha_{1}\right)\left(L^{L}-D_{2}\right)=\left(1-\alpha_{1}\right)\left(G_{B}^{L}-L^{L}\right)+F>0
$$

must hold. Given our assumptions as to the first-best continuation decisions, this condition always holds.

In contrast, the H-project will not be continued if the debt claim $D_{2}$ exceeds the liquidation value of the H-project $\left(L^{H}\right)$ which in turn is higher than the expected value of the contractible part of the growth option:

$$
D_{2}>L^{H}>G_{B K}^{H}
$$

In this case, which we assume to hold, debtholders receive $L^{H}$ by liquidating the project and cannot be compensated in the course of renegotiating the debt contract.

The actual continuation decisions are summarized in the following table ( $\mathrm{C}$ standing for continuation and DC for liquidation)

Figure 2: Summary of continuation decisions

\begin{tabular}{c|ccccc} 
& \multicolumn{2}{|c}{ Debt in stage 1 } & \multicolumn{2}{c}{ Equity in stage 1 } \\
& D in stage 2 & E in stage 2 & D in stage 2 & E in stage 2 \\
\hline L-/H-project in G-state & $\mathrm{C}$ & $\mathrm{C}$ & $\mathrm{C}$ & $\mathrm{C}$ \\
\hline L-project in B-state & $\mathrm{DC}$ & $\mathrm{C}$ & $\mathrm{C}$ & $\mathrm{C}$ \\
H-project in B-state & DC & $\mathrm{C}$ & $\mathrm{DC}$ & $\mathrm{C}$
\end{tabular}

Furthermore, our assumptions regarding the relations of the different payoffs can be summarized as follows:

$$
\begin{gathered}
G_{B}^{L}>G_{B}^{L}(D) \\
G_{B}^{L}(D)+F>L^{L}>L^{H}>G_{B}^{H}+F \\
H>D_{1}+D_{2}>L^{L}>G_{B K}^{L}>G_{B K}^{L}(D)>G_{B K}^{H}>D_{1} \\
G_{B K}^{L}>D_{2}>L^{H}>G_{B K}^{H} \\
L^{H}<G_{B}^{H}+\frac{F}{1-\alpha_{2}}
\end{gathered}
$$


In addition, we assume that the financing choices and the thereby induced continuation decisions do not alter the order of the E's expected payoffs of the three projects. In a nutshell this implies that any distortions caused by the financing choices are not strong enough to alter the order of expected payoffs of the three projects. Though, this does not mean that the project choice decision becomes irrelevant as E always compares the safe project with the expected total payoffs of the risky projects and this relation changes depending on the financing choices. More specifically, this implies that the following assumptions hold:

$$
\begin{gathered}
\left(1-\tau_{H}\right)\left(H+G^{H}\right)+\tau_{H}\left(L^{H}-F\right)<H+G^{S}<\left(1-\tau_{L}\right)\left(H+G^{L}\right)+\tau_{L} G_{B}^{L}(D) \\
\left(1-\tau_{H}\right)\left(H+G^{H}+F-D_{1}-D_{2}\right)<\left(1-\tau_{L}\right)\left(H+G^{L}+F-D_{1}-D_{2}\right) \\
\left(1-\tau_{H}\right)\left(H+G^{H}+\tau_{H} G_{B}^{H}<\left(1-\tau_{L}\right)\left(H+G^{L}\right)+\tau_{L} G_{B}^{L}(D)\right. \\
\left(1-\tau_{H}\right)\left(H+G^{H}-D_{2}\right)-\tau_{H} \frac{F}{1-\alpha_{1}}<\left(1-\tau_{L}\right)\left(H+G^{L}\right)+\tau_{L} G_{B}^{L}-D_{2}
\end{gathered}
$$

\section{The choice between the risky projects and the safe project at the expansion stage}

At $t=4$, the entrepreneur has the possibility to define his expansion strategy. In terms of our model, this corresponds to the choice between the risky projects and the safe project. Thereby, he anticipates the continuation decisions. As the continuation decisions depend on the financing choices at both the start-up and the expansion stages, we have to distinguish four cases.

Debt-debt financing. Given that the entrepreneur has chosen debt financing at the start-up stage and the expansion stage (which we refer to as debt-debt financing, whereby the first (second) expression describes the financing mode chosen at the start-up (expansion) stage), he anticipates that both types of risky projects will be discontinued at $t=5 \mathrm{in}$ the B-state. Taking into account the debt claims of both stages $\left(D_{1}\right.$ and $D_{2}$, respectively), the E's expected profit from realizing the risky projects is given by

$$
q\left[\left(1-\tau_{H}\right)\left(H+G^{H}-D_{1}-D_{2}+F\right)\right]+(1-q)\left[\left(1-\tau_{L}\right)\left(H+G^{L}-D_{1}-D_{2}+F\right)\right] .
$$

Note that with both types of risky projects, the liquidation gain in the B-state goes completely to the investors. Moreover, E can only realize his private continuation profit $F$ in the successful states but not in the B-states because both projects will be discontinued. When realizing the safe project, the E's profit is given by

$$
H+G^{S}-D_{1}-D_{2}+F .
$$


Comparing the expected profit from realizing the risky projects with the profit from realizing the safe project yields us the following critical value for the percentage of $\mathrm{H}$ projects in the economy for which $\mathrm{E}$ is just indifferent between the two options:

$$
\tilde{q}_{D, D}=\frac{G^{L}-G^{S}-\tau_{L}\left(H+G^{L}-D_{1}-D_{2}\right)}{\left(1-\tau_{L}\right)\left(H+G^{L}+F-D_{1}-D_{2}\right)-\left(1-\tau_{H}\right)\left(H+G^{H}+F-D_{1}-D_{2}\right)} .
$$

We will refer to this value as the critical quality of the risky project with pure debt financing. If the actual quality is poorer (i.e. $q$ is larger), then the entrepreneur will choose the safe project because the expected profit of the risky projects decreases due to a higher percentage of less valuable H-projects in the pool.

Analogously, we can now analyze the decision for the other three financing decisions. Debt-equity financing. With debt financing at the start-up stage and equity financing at the expansion stage, neither of the risky projects will be discontinued at $t=5$. Taking into account the debt claim $D_{1}$ of the first stage and the equity claim $\alpha_{2}$ of the second stage, E will opt for the safe project if

$$
\begin{aligned}
\left(1-\alpha_{2}\right)\left\{H+G^{S}-D_{1}\right\} \geq & \left(1-\alpha_{2}\right)\left\{q\left[\left(1-\tau_{H}\right)\left(H+G^{H}-D_{1}\right)+\tau_{H}\left(G_{B}^{H}-D_{1}\right)\right]+\right. \\
& \left.(1-q)\left[\left(1-\tau_{L}\right)\left(H+G^{L}-D_{1}\right)+\tau_{L}\left(G_{B}^{L}(D)-D_{1}\right)\right]\right\} .
\end{aligned}
$$

Due to renegotiation in the B-state, E will be able to pay the total debt claim $D_{1}$ independently of the state of the project and the type of risky project. Moreover, the choice of debt financing in the first stage comes with commitment costs which reduce the expected value of the growth option of the L-project in the B-state from $G_{B}^{L}$ to $G_{B}^{L}(D)$. We get the following critical quality for the risky projects for which $\mathrm{E}$ is just indifferent between the risky projects and the safe project:

$$
\tilde{q}_{D, E}=\frac{G^{L}-G^{S}-\tau_{L}\left(H+G^{L}-G_{B}^{L}(D)\right)}{\left(1-\tau_{L}\right)\left(H+G^{L}\right)+\tau_{L} G_{B}^{L}(D)-\left[\left(1-\tau_{H}\right)\left(H+G^{H}\right)+\tau_{H} G_{B}^{H}\right]} .
$$

Equity-equity financing. If $\mathrm{E}$ has financed the project with pure equity (i.e. equity at both the start-up and the expansion stages), then we can write the E's decision as follows:

$$
\begin{array}{r}
\left(1-\alpha_{1}\right)\left(1-\alpha_{2}\right)\left\{H+G^{S}\right\} \geq\left(1-\alpha_{1}\right)\left(1-\alpha_{2}\right)\left\{q\left[\left(1-\tau_{H}\right)\left(H+G^{H}\right)\right]+\tau_{H} G_{B}^{H}\right. \\
\left.(1-q)\left[\left(1-\tau_{L}\right)\left(H+G^{L}\right)+\tau_{L} G_{B}^{L}\right]\right\} .
\end{array}
$$

With pure equity financing - just as in the case of debt-equity financing - neither of the risky projects is discontinued in the B-state at $t=5$. Again, we can write the critical quality of the risky projects for which $\mathrm{E}$ is just indifferent between the two options as:

$$
\tilde{q}_{E, E}=\frac{G^{L}-G^{S}-\tau_{L}\left(H+G^{L}-G_{B}^{L}\right)}{\left(1-\tau_{L}\right)\left(H+G^{L}\right)+\tau_{L} G_{B}^{L}-\left[\left(1-\tau_{H}\right)\left(H+G^{H}\right)+\tau_{H} G_{B}^{H}\right]} .
$$


Equity-debt financing. Finally, if E has opted for equity at the start-up stage and subsequently switched to debt financing at the expansion stage, his expected profit from realizing the risky projects is given by:

$$
\begin{aligned}
& \left(1-\alpha_{1}\right)\left\{q\left[\left(1-\tau_{H}\right)\left(H+G^{H}-D_{2}\right)\right]+\right. \\
& \left.\quad(1-q)\left[\left(1-\tau_{L}\right)\left(H+G^{L}-D_{2}\right)+\tau_{L}\left(G_{B}^{L}-D_{2}\right)\right]\right\}+\left(1-q \tau_{H}\right) F .
\end{aligned}
$$

In this case, only the $\mathrm{H}$-project is discontinued in the B-state at $t=5$ while the L-project is continued. This implies further that $\mathrm{E}$ will loose his private continuation profit $\mathrm{F}$ in this state whereas in all other states he can conserve it as the projects are continued. The continuation profit is private and is thus not shared with the equity investor neither. Finally, as $D_{2}>L^{H}$, the whole liquidation gain of the H-project will go to the debtholders. Comparing the expected profit of the risky projects with the profit of the safe project gives us the following critical quality of the risky projects for which $\mathrm{E}$ is just indifferent between the two options:

$$
\tilde{q}_{E, D}=\frac{G^{L}-G^{S}-\tau_{L}\left(H+G^{L}-G_{B}^{L}\right)}{\left(1-\tau_{L}\right)\left(H+G^{L}\right)+\tau_{L} G_{B}^{L}-\left[\left(1-\tau_{H}\right)\left(H+G^{H}\right)+\tau_{H}\left(D_{2}-\frac{F}{\left(1-\alpha_{1}\right)}\right)\right]} .
$$

As for all the critical values of $\mathrm{q}, \mathrm{E}$ will choose the safe (risky) project if $\mathrm{q}$ is larger (smaller). This is due to the fact that the expected value of the H-projects is always smaller than the expected value of the L-projects (see assumptions A6-A9) and thus, the total expected value of the risky projects decreases with an increase of the percentage of H-projects.

\section{The choice between debt and equity financing at the expansion stage}

The purpose of this section is to analyze the choice between debt and equity financing at the expansion stage. Therefore, we will compare the final outcomes induced by both financing options taking into account the subsequent project choice at $t=3$ as well as the continuation decisions at $t=5$. The firm, already being in its expansion stage, takes the financing decisions at the start-up phase as given.

\subsection{Equity financing at the start-up stage}

We will begin by analyzing the financing decision taking into account the existence of equity investors with a share of $\alpha_{1}$ in the firm. Equity financing at the start-up stage modifies the initial situation as it introduces an asymmetry between monetary and private benefits at the expansion stage. E has to share all monetary returns of the project with the 
equity investors of the first stage but not his private continuation profit F. Therefore, he will value a loss of his private continuation profit relatively higher than an equivalent loss in monetary returns. The size of the expected overvaluation of the private continuation profit depends on the equity stake of the start-up stage investors $\alpha_{1}$.

In order to be able to analyze the E's optimal financing choice, we have to determine the differences between debt and equity financing at the expansion stage. Therefore, in a first step, we will compare the impact of debt and equity financing on the total expected payoffs of the risky projects taking account of the continuation decisions at $t=5$ which are induced by each financing alternative. Whereas the L-project is always continued independently of the form of financing at the expansion stage, debt financing implies the liquidation of the H-project in the B-state and equity financing its continuation. Blinding out the start-up stage, the continuation of the H-project produces an expected loss in the total payoff of the risky projects of

$$
q \tau_{H}\left[L^{H}-G_{B}^{H}-F\right]=N T
$$

However, besides this non-termination effect (NT), we have to consider that the loss of the private continuation profit caused by the liquidation of the $\mathrm{H}$-project is overvalued by the entrepreneur due to the initial equity stake $\alpha_{1}$. This implies that $\mathrm{E}$ associates an additional gain of

$$
q \tau_{H}\left[\frac{F}{\left(1-\alpha_{1}\right)}-F\right]=O V
$$

to the continuation of the $\mathrm{H}$-project relative to its liquidation. In what follows, we will refer to this effect as the overvaluation effect (OV).

Furthermore, we have to take account of an additional effect of debt financing: the risk-shifting effect. This effect arises because E takes the financing decision as given when he makes his project choice at $t=3$ and thus, his limited liability induces a gain with the risky projects relative to the safe project which is given by

$$
q \tau_{H}\left(D_{2}-L^{H}\right)=R S(E)
$$

This gain increases the value of the risky projects relative to the safe project from an ex-post point of view and thus, E will be more inclined to opt for the risky projects.

In addition, it turns out to be helpful to define the critical share, given liquidation of the H-project, which makes E just indifferent between the risky and the safe project from an ex ante point of view, i.e. with fairly priced claims for both the risky projects as well as the safe project (see appendix A for a detailed derivation):

$$
\tilde{q}_{E}^{S B(T)}=\frac{G^{L}-G^{S}-\tau_{L}\left(H+G^{L}-G_{B}^{L}\right)}{\left(1-\tau_{L}\right)\left(H+G^{L}\right)+\tau_{L} G_{B}^{L}-\left[\left(1-\tau_{H}\right)\left(H+G^{H}\right)+\tau_{H}\left(L^{H}-\frac{F}{\left(1-\alpha_{1}\right)}\right)\right]}
$$


The interaction of these three mechanisms finally determines the financing choices at the expansion stage. While the non-termination and the overvaluation effect determine the financing choices via (dis)continuation of the H-project, the risk-shifting effect implies a cost of debt financing which works through the project choice leading to a selection of the risky project in too many cases. The following lemma (which we prove in appendix B) sums up the optimal financing decisions in dependence of the interaction of the described mechanisms:

Lemma 1 The optimal financing decision depends on the relative size of the $O V, N T$ and $R S(E)$ effects. We can distinguish two main cases:

1. $O V \leq N T: E$ will always choose debt to finance the risky projects (i.e. for $q \leq$ $\left.\tilde{q}_{E}^{S B(T)}\right)$. For higher values of $q$ (i.e. $\left.\tilde{q}_{E}^{S B(T)}<q \leq \tilde{q}_{E, D}\right)$, E will choose equity to induce the choice of the safe project. For $q>\tilde{q}_{E, D}, E$ is indifferent between debt and equity to finance the safe project which will be chosen independently of the financing form.

2. $O V>N T$ : E will always choose equity to finance the risky projects (i.e. for $q \leq$ $\left.\tilde{q}_{E, E}\right)$.

a) $N T \geq O V-R S(E)$ : E will choose equity to induce the choice of the safe project for $\tilde{q}_{E, E}<q \leq \tilde{q}_{E, D}$. For $q>\tilde{q}_{E, D}, E$ is indifferent between debt and equity to finance the safe project which will be chosen independently of the financing form.

b) $N T(E)<O V-R S(E)$ : E is indifferent between debt and equity to finance the safe project which he anticipates to choose at $t=3$ for $q>\tilde{q}_{E, E}$.

The intuition behind this lemma is the following. The fact that equity financing of the firm at the start-up phase leaves only the share $\left(1-\alpha_{1}\right)$ of all monetary payoffs with $\mathrm{E}$ while he fully benefits from control benefits in case of the continuation of the H-project may make it worthwhile for $\mathrm{E}$ to continue the H-project at the expansion stage. This is the case if the non-termination effect (depicting the costs of continuing the H-project from an overall point of view) is smaller than the overvaluation effect (depicting the relative higher importance of non-monetary control benefits for $\mathrm{E}$ if the H-project is continued). If, in turn, however, the NT effect is larger than the OV effect, it is optimal to discontinue the H-project - even at the expansion stage (i.e. from what can be called a second best alternative).

If the non-termination effect dominates the overvaluation effect (case 1 of lemma 1), E has thus a preference for debt financing in order to induce the efficient liquidation of the H-project. For $q<(>) \tilde{q}_{E}^{S B(T)}$, the risky (safe) project should be chosen. In the absence of the risk-shifting effect, debt, which leads to a liquidation of the H-project, is optimal. But due to the risk-shifting effect, debt leads too often to the choice of the risky projects. 
Hence, the choice of equity in the expansion stage (for $q \in\left(\tilde{q}_{E}^{S B(T)}, \tilde{q}_{E, D}\right)$ ) is nothing but a commitment to chose the safe project and to avoid risk-shifting.

If the overvaluation effect dominates the non-termination effect (case 2 of lemma 1), it is optimal for $\mathrm{E}$ to go for the continuation of the H-project at the expansion stage. In this case, equity is always superior to finance the risky projects (i.e. for $q \leq \tilde{q}_{E, E}$ - the critical share with pure equity financing) in the expansion phase. Otherwise, the safe project should be chosen and thus E should be indifferent between both financing forms. Though, this is only the case if the risk shifting effect is weak (case $2 \mathrm{~b}$ ). If the risk-shifting effect is strong, equity will be chosen once again to avoid the risk shifting effect (for $\left.q \in\left(\tilde{q}_{E, E}, \tilde{q}_{E, D}\right)\right)$. This is the case if the risk-shifting effect of debt is larger than the difference between the non-termination and the overvaluation effect implying smaller expected cash-flows of the risky projects with debt financing.

\subsection{Debt financing at the start-up stage}

We now turn to the second scenario of financing decisions at the expansion stage by taking into account the existence of a debtholder with a claim of $D_{1}$ in the firm. Debt financing at the start-up stage modifies the initial situation as it introduces a reduction of the expected value of the L-project's growth option in the B-state from $G_{B}^{L}$ to $G_{B}^{L}(D)$. This is due to the fact that the debtholder can force the entrepreneur to adjust his growth strategy in order to reduce default risk. Apart from this commitment effect, debt differs from equity financing at the start-up stage as with debt financing neither of the financing options induces the efficient (first-best) continuation decisions of the risky projects in $t=5$. With equity (debt) both projects will be (dis-)continued.

In order to be able to analyze the E's optimal financing choice, we have to determine again the differences between debt and equity financing at the expansion stage. Therefore, in a first step, we compare the impact of debt and equity financing on the expected total payoffs of the risky projects. With equity financing, we are confronted with an inefficient continuation of the H-project which reduces the expected total payoffs of the risky projects by

$$
q \tau_{H}\left(L^{H}-G_{B}^{H}-F\right)=N T
$$

This non-termination effect is equivalent to the one arising with pure equity financing. Debt financing, on the other hand, induces an inefficient liquidation of the L-project which again reduces the expected total payoffs of the risky projects. This expected loss which we name risk-avoidance effect is given by

$$
(1-q) \tau_{L}\left(G_{B}^{L}(D)+F-L^{L}\right)=R A
$$


Both, the non-termination as well as the risk-avoidance effect, depend on the value of $\mathrm{q}$, i.e. the percentage of H-projects in the economy. But whereas the non-termination effect increases in value with a higher share of H-projects, the opposite is true for the riskavoidance effect. This is rather obvious, given that the non-termination effect reflects the inefficient continuation of $\mathrm{H}$-projects while the risk-avoidance effect depicts the inefficient liquidation of L-projects. Thus, there must exist a critical $\hat{q}(D)$ for which both effects are equal (see appendix $\mathrm{C}$ for a detailed derivation)

$$
\hat{q}(D)=\frac{\tau_{L}\left(G_{B}^{L}(D)+F-L^{L}\right)}{\tau_{L}\left(G_{B}^{L}(D)+F-L^{L}\right)+\tau_{H}\left(L^{H}-G_{B}^{H}-F\right)}
$$

Furthermore, we have to take account of the additional risk-shifting effect of debt financing. Just as in the case of equity financing at the start-up stage, this effect arises because $\mathrm{E}$ takes the financing decision as given when he makes his project choice at $t=3$ and thus, his limited liability in combination with the risky debt-claim induces a gain with the risky projects relative to the safe project which is given by

$$
q \tau_{H}\left(D_{1}+D_{2}-L^{H}\right)+(1-q) \tau_{L}\left(D_{1}+D_{2}-L^{L}\right)=R S(D) .
$$

In addition, it is helpful to compare the total expected payoff of the risky projects with liquidation of both risky projects in the B-state (i.e. the expected payoff with pure debt financing, neglecting the risk-shifting effect) with the total payoff of the safe project $\left(H+G^{S}+F\right)$. This comparison yields the critical value for debt financing (see appendix $\mathrm{D}$ for a detailed derivation):

$$
\tilde{q}_{D}^{S B(T, T)}=\frac{G^{L}-G^{S}-\tau_{L}\left[H+G^{L}-L^{L}-F\right]}{\left(1-\tau_{L}\right)\left(H+G^{L}\right)+\tau_{L}\left(L^{L}-F\right)-\left(1-\tau_{H}\right)\left(H+G^{H}\right)-\tau_{H}\left(L^{H}-F\right)}
$$

Note that since the claims of the expansion stage investor are fairly priced in both cases and debt at the first stage is riskless, we are able to compare only expected total payoffs.

The optimal financing decisions at the expansion stage after debt financing at the start-up stage finally depend on the relative impact of the non-termination effect (NT), the risk-avoidance effect (RA) and the risk-shifting effect (RS(D)) and are summed up in the following lemma which we prove in appendix E:

Lemma 2 As to the optimal financing decisions at the expansion stage after debt financing, we can distinguish the following two main cases:

1. $N T \geq R A$ for $\tilde{q}_{D}^{S B(T, T)}$ : E will always choose equity financing for rather small values of $q(q<\hat{q}(D))$ and debt financing for $q \in\left(\hat{q}(D) ; \tilde{q}_{D}^{S B(T, T)}\right)$ to finance the risky projects. For $\tilde{q}_{D}^{S B(T, T)} \leq q<\tilde{q}_{D, D}$, E uses equity financing in order to induce the choice of the safe project. Finally, for $q \geq \tilde{q}_{D, D}, E$ is indifferent between debt and equity to finance the safe project. 
2. $N T<R A$ for $\tilde{q}_{D}^{S B(T, T)}$ : E will always choose equity financing in order to finance the risky projects (i.e. $\left.q \leq \tilde{q}_{D, E}\right)$.

a) $R A-R S(D) \leq N T<R A$ for $\tilde{q}_{D, E}$ : E will choose equity to induce the choice of the safe project for $\tilde{q}_{D, E}<q \leq \tilde{q}_{D, D}$. For $q>\tilde{q}_{D, D}$, $E$ is indifferent between debt and equity to finance the safe project which will be chosen independently of the financing form.

b) $N T<R A-R S(D)$ for $\tilde{q}_{D, E}$ : E is indifferent between debt and equity to finance the safe project for $q>\tilde{q}_{D, E}$.

The intuition behind this lemma can be best understood by realizing that the NT effect depicts the cost of equity (namely the fact that with equity the H-project is inefficiently continued), whereas the RA effect delineates a cost of debt financing (the L-project is inefficiently discontinued with pure debt financing). While these two effects are related to inefficient (dis-)continuation decisions, the risk-shifting effect of debt comes with the inefficient project choice (leading, ceteris paribus, to too much risk-taking with pure debt). Furthermore, it has to be noted that the relative weight of the NT and the RA effects depends on the share of the H-project. The larger is q, the more important is the NT effect compared to the RA effect since the former inefficiency comes with H-projects, while the latter stems from the L-projects. Therefore, the choice of the financing mode crucially depends on the relative importance of the RA and the NT effect with the critical share of the H-project with pure debt financing excluding the risk-shifting effect, $q=\tilde{q}_{D}^{S B(T, T)}$.

If the cost of equity financing (the NT effect) is larger than the one of debt financing (the RA effect) at this point (lemma 2, case 1), then it pays to finance risky projects for smaller q's with equity and for larger q's with debt. This is due to the fact that the weight of the NT relative to the RA effect decreases with q and thus, equity financing of risky projects dominates for sufficiently small values of $\mathrm{q}(q \leq \hat{q}(D))$ while for $q \in$ $\left(q_{\bar{D}, E}, \tilde{q}_{D}^{S B(T, T)}\right)$ debt financing is optimal. However, as debt financing induces the described risk-shifting effect, equity financing will again be chosen for $\tilde{q}_{D}^{S B(T, T)} \leq q<\tilde{q}_{D, D}$ in order to commit to the choice of the safe project and thus avoid the risk-shifting effect.

If in contrast, the NT effect is smaller than the RA effect as in case 2 of the above lemma 2 , it is always optimal to finance the risky projects with equity. This implies, even when excluding risk-shifting, higher costs of debt financing compared to equity financing in the expansion stage; or more technically speaking $\tilde{q}_{D}^{S B(T, T)}<\tilde{q}_{D, E}$.

If the risk-shifting effect is weak (case $2 \mathrm{~b}$ ), $\tilde{q}_{D, D}<\tilde{q}_{D, E}$, there is no need to use equity financing as a commitment device to choose the safe project. This is only the case with a more pronounced risk-shifting effect (case 2a), leading to $\tilde{q}_{D, D}>\tilde{q}_{D, E}$ and therefore the need to finance the safe project with equity for $q \in\left(\tilde{q}_{D, E}, \tilde{q}_{D, D}\right)$. In all other cases, $\mathrm{E}$ is indifferent between debt and equity to finance the safe project. 


\section{The choice between debt and equity financing at the start-up stage}

Finally, when looking on the E's financing choice at the start-up stage, we have to distinguish four effects which determine the choice between debt and equity financing at the first stage. These effects can be classified in two groups. First, the effects which define the initial situation for $\mathrm{E}$ at the expansion stage: the overvaluation effect $(\mathrm{OV})$ and the commitment cost effect (CC). We can state both effects as the expected total loss implied through the overvaluation of the private continuation gain in case of liquidation of the H-project as well as through the adjustment of the expansion strategy, respectively as:

$$
\begin{aligned}
O V & =q \tau_{H}\left[\frac{F}{\left(1-\alpha_{1}\right)}-F\right] \\
C C & =(1-q) \tau_{L}\left[G_{B}^{L}-G_{B}^{L}(D)\right]
\end{aligned}
$$

Whereas the OV effect depicts a cost of equity financing in the start-up stage (leading potentially to excessive continuation of the $\mathrm{H}$-project), the $\mathrm{CC}$ effect depicts a cost of debt financing in the first stage. This commitment cost effect arises because the debtholders of the start-up stage can force $\mathrm{E}$ to adjust his expansion strategy to reduce default risk although this adjustment reduces the expected value of the L-project's growth option in the B-state.

Furthermore, we have to consider the effects which govern the financing choice at the second stage: the risk-avoidance effect (RA) and the non-termination effect (NT).

$$
\begin{aligned}
R A & =(1-q)\left[G_{B}^{L}(D)+F-L^{L}\right] \\
N T & =q\left[L^{H}-G_{B}^{H}-F\right]
\end{aligned}
$$

Note that the risk-shifting effect is irrelevant for the financing choice at the start-up stage as it does not manifest in equilibrium (see section 5 ).

In addition, it turns out to be helpful to define the critical value of $q$ for which the monetary costs of equity financing (NT effect) just equal the monetary costs of debt financing ( $\mathrm{RA}+\mathrm{CC}$ effects) given by

$$
\hat{q}=\frac{\tau_{L}\left(G_{B}^{L}+F-L^{L}\right)}{\tau_{L}\left(G_{B}^{L}+F-L^{L}\right)+\tau_{H}\left(L^{H}-G_{B}^{H}-F\right)}
$$

The financing decision at the start-up stage depends on the relatives magnitudes of the described four effects.

We prove in appendix F:

Proposition 3 As to the optimal financing choice at the start-up stage, we can distinguish two main cases: 

1. If $\underset{\tilde{q}_{E}^{S B(T)}}{O S} \leq N T, E$ will always choose equity financing at the start-up stage for $q \leq$

a) If $O V \geq R A+C C$ for $\tilde{q}_{D}^{S B(T, T)}$, then he will prefer debt financing for $\tilde{q}_{E}^{S B(T)}<$ $q \leq \tilde{q}_{D}^{S B(T, T)}$ in order to induce the choice of the risky projects. For $q>\tilde{q}_{D}^{S B(T, T)}$, $E$ is indifferent between the financing forms anticipating that the safe project will always be chosen.

b) Otherwise, if $O V<R A+C C$ for $\tilde{q}_{D}^{S B(T, T)}$, E is indifferent between the financing forms anticipating that the safe project will always be chosen for $q>\tilde{q}_{E}^{S B(T)}$.

2. If $O V>N T$, the E's financing choice at the start-up stage depends on the relative magnitudes of the risk-avoidance effect, the non-termination effect as well as the commitment cost effect.

a) If $R A+C C<N T$ for $\tilde{q}_{D}^{S B(T, T)}$, E will choose debt financing in order to commit ex ante to realize the risky projects for $\tilde{q}^{E, E}<q \leq \tilde{q}_{D}^{S B(T, T)}$. For $\hat{q}<q \leq \tilde{q}_{E, E}$, $E$ will choose debt financing in order to commit ex ante to discontinue the $H$ project. Though, for $q \leq \hat{q}, R A+C C \geq N T$, and thus $E$ will choose start-up equity financing. Finally, for $q>\tilde{q}_{D}^{S B(T, \bar{T})}$, E is indifferent between the financing forms anticipating that the safe project will always be chosen.

b) If $R A+C C \geq N T$ for $\tilde{q}_{D}^{S B(T, T)}$, E will always choose equity financing for $q \leq$ $\tilde{q}_{E, E}$. For $q>\tilde{q}_{E, E}$, he is indifferent between the financing forms anticipating that the safe project will always be chosen.

Before we discuss the intuition of this main proposition of the paper, it is important to recall that our set-up is chosen such that equity financing in the first stage has an important advantage: it may lead to the optimal continuation decisions if it is followed by debt financing in the expansion stage (see table 2). This is exactly the implication of case 1 of the above proposition. If the OV effect is smaller than the NT effect, then E anticipates that equity financing in the first stage will not only lead to debt financing in the expansion stage, but also to efficient continuation decisions. Hence, it is optimal to choose equity in the first stage for $q \leq \tilde{q}_{E}^{S B(T)}$, foreseeing that this will lead to the choice of the risky project.

However, if equity-debt financing will lead to the implementation of the safe project, it may be optimal to avoid the implementation of the safe project by using debt financing in the first stage. This is due to the fact that with equity in the first stage (and debt in the second), a strong overvaluation effect makes the risky projects unattractive (hence, leading to the inefficient choice of the safe project). However, for debt financing at the start-up stage to be more attractive, the cost of debt (the risk avoidance effect and the commitment costs) has to be rather small leading to the choice of the risky project with pure debt financing (case 1a).

If the OV effect is larger than the NT effect, equity in the start-up stage will be followed by equity financing in the expansion stage in order to finance the risky projects (see 
lemma 1). Hence, the advantage of equity financing, namely to achieve efficient liquidation decisions (via equity-debt financing) cannot be implemented. As debt-equity financing induces the same continuation decisions as pure equity financing in our model but induces additionally commitments costs, debt financing is only chosen at the start-up stage if $\mathrm{E}$ prefers pure debt financing to pure equity financing. This is the case if the costs of debt financing (RA and CC effects) are sufficiently small relative to the cost of equity financing (NT effect). Here, E chooses debt financing to commit to realize the risky projects and to discontinue the H-project in the B-state (case 2a). On the contrary, if these costs are relatively large, equity financing in the first stage will be chosen to finance the risky projects (case $2 \mathrm{~b}$ ).

To sum up, we can thus state that one of the main results of proposition 3 is that even if equity allows the efficient continuation decisions to be implemented, the entrepreneur may have an incentive to choose debt financing as a commitment device in order to discontinue the $\mathrm{H}$-project in the B-state.

\section{The impact of the lack of financing possibilities}

In this section, we will discuss the impact of financing constraints in the expansion as well as the start-up stages. These constraints may result from institutional barriers and limitations or from unfavorable market conditions. Thereby, we will distinguish three cases. First, a particular country may be lacking a sufficiently developed venture capital market implying that start-up firms have little or no access to start-up equity financing. Second, we consider the case in which the banking sector may not be able to invest in the start-up stage because it does not hold an adequate screening and monitoring technology to finance these firms. Third, we will look at economies where the stock market is not sufficiently developed and thus, firms do not have access to equity financing at the expansion stage. In what follows, we will briefly discuss how this lack of financing possibilities affects the outcome of the risky projects as well as the project choice decision.

\subsection{Lack of access to start-up equity financing}

The main source of external equity financing at the start-up stage is typically venture capital given that young firms do not have access to organized capital markets. If the venture capital market is, however, little developed, this source of financing is not available to firms. What are the consequences on financing choices, project choice and firm dynamics?

Looking at lemma 2 and proposition 3 reveals the following. If the overvaluation effect is smaller than the non-termination effect (case 1 of proposition 3), the expected payoff 
of the risky projects is maximized with start-up equity financing. A lack of start-up equity financing reduces the value of the risky projects due to inefficient continuation decisions. In addition, the risky projects are realized less frequently compared to start-up equity financing. Thus, a lack of start-up equity financing reduces the number of realized innovations in an economy. If the overvaluation effect is pronounced (i.e. $O V>N T$, see case 2 of proposition 3), the negative impact of a lack of start-up equity financing is smaller. This is due to the fact that E cannot commit to choose debt financing at the expansion stage after equity financing at the start-up stage to induce the first-best continuation decisions. Consequently, the only additional costs which may arise with startup debt financing are the commitment costs. Although these additional costs may reduce both the expected payoff of the risky projects as well as the frequency of realization of the risky projects per se, the effects are definitively smaller than in the first case. In addition, they mainly manifest if pure debt financing is costly (case $2 \mathrm{~b}$ of proposition 3 ). Thus, whenever, the agency costs of equity financing are significantly lower than the ones of debt financing, the impact of a lack of a venture capital market will be especially crucial leading to less implementation of risky projects and thus fewer fast-growing firms.

\subsection{Lack of access to start-up debt financing}

Due to the lack of a proper monitoring and screening technology of banks, there may not exist the possibility of start-up debt financing. Comparing lemma 1 and proposition 3 underlines that even though only start-up equity financing may implement the first-best continuation decisions, a lack of start-up debt financing may also worsen the outcome. This is due to the fact that the entrepreneur cannot resort anymore to start-up debt financing as a commitment device to discontinue the H-project in the B-state nor to realize the risky projects. Consequently, if the overvaluation effect is rather strong and the costs of pure debt financing are rather small (case 2a of proposition 3), a lack of startup debt financing reduces the expected payoff of the risky projects and, in addition, the risky projects are realized less frequently. Furthermore, even if E can commit to induce the efficient continuation decisions, he also chooses the safe project relatively less often with start-up equity financing if the costs of pure debt financing are rather small with respect to the costs of start-up equity financing (see case 1a of proposition 3). Thus, a lack of start-up debt financing may also reduce the innovation activity in an economy if the financing costs associated to debt (RA and $\mathrm{CC}$ ) are rather small in comparison to the costs of equity financing (NT and OV).

Comparing both cases of lack of start-up financing shows that the costs of pure debt financing relative to the costs of equity financing determine the magnitude of both effects. If start-up debt financing is rather cheap with respect to start-up equity financing, then a 
lack of start-up equity financing is less severe. However, in this case a lack of start-up debt financing can be crucial. The reverse is true if start-up debt financing is rather expensive, i.e. the RA and the $\mathrm{CC}$ effects are pronounced with respect to the NT and OV effect. Furthermore, the impact of a lack of start-up financing depends on the quality of the risky project: if its quality is rather high (i.e. $q$ is rather low), a lack of start-up debt financing may be less severe than with medium quality projects.

\subsection{Lacking equity financing at the expansion stage - the case of an underdeveloped stock market}

Finally, we will analyze the situation where it is not possible to obtain equity financing at the expansion stage. This is especially pronounced if the stock market is underdeveloped or not accessible as a source of firm financing, due to market conditions. Indeed, we may distinguish two situations. First of all, we consider the situation where expansion stage equity financing is never available. In this case, the advantage of start-up equity financing is reenforced because the commitment problem of $\mathrm{E}$ is indirectly solved. If $\mathrm{E}$ chooses start-up equity financing, he automatically decides for expansion stage debt financing (i.e. case 2 of proposition 3 does not exist) and thus the efficient (first-best) continuation decisions of the risky projects. This means that the value of start-up debt financing as a commitment device to discontinue the $\mathrm{H}$-project in the B-state vanishes. As debt as a commitment device was costly, the outcome now improves: the risky projects become more profitable and are realized more frequently. Hence, we get a surprising result: limited access to equity in the expansion stage leads firms to equity-finance their start-up stage leading to more innovation and projects with high potential dynamics.

However, we also would like to consider the case in which only firms that have been financed by private equity investors at the start-up stage will be able to receive financing from such type of investors at the expansion stage, too. In this case, only firms which choose debt financing at the start-up stage would be limited in their financing decision at the expansion stage, i.e. the choice of start-up debt financing would always imply the choice of debt financing at the expansion stage. Analyzing proposition 3 shows that while this lack of expansion stage equity financing may have an influence on the financing choice after start-up debt financing it does not have any impact on the overall financing decision. This is due to the fact that start-up debt financing is only preferred to start-up equity financing if the advantage of pure debt financing is pronounced as debt-equity financing is always dominated by pure equity financing.

Thus, in our context, a lack of financing possibilities at the expansion stage has hardly any effects and may even be positive. This is, however, also due to the fact that there is no further financing decision to be taken afterwards in our model. 
To sum up, we can state that it is the lack of financing possibilities at the start-up stage which reduces the innovation activity in an economy - both with respect to the value of the innovations as well as the realization of innovations. Interestingly, this is valid for both equity and debt financing.

\section{Empirical Implications}

Having a closer look at proposition 3 shows that there are three different financing sequences for the risky projects in equilibrium: debt financing at both financing stages (case $2 \mathrm{a}-O V>N T>R A+C C$ ), equity financing at both financing stages (case $2 \mathrm{~b}$ - $O V>N T$ and $R A+C C>N T$ ), or equity financing at the start-up stage and debt financing at the expansion stage (case $1-O V<N T$ ). The importance of each of these cases depends on the relative magnitude of the NT effect, the RA effect, the CC effect as well as the OV effect. In what follows, we aim at operationalizing these effects in order to be able to deduce testable hypothesis.

The overvaluation effect depends positively on the E's private control benefits $F$ as well as the equity stake of the start-up stage $\alpha_{1}$. Private control benefits should be lower for so called professional entrepreneurs as well as in widely-held companies and higher in closely-held firms like, for example, family firms. In addition, we interpret $F$ as an additional cost for $\mathrm{E}$ in case of liquidation, i.e. some sort of stigmatization cost. The startup equity stake depends on the need of the entrepreneur to demand outside capital to get his project financed. The higher these dependence of outside financing, the higher should be the overvaluation effect. Here, beside the financial endowment of $\mathrm{E}$ (i.e. the amount of his savings or his access to money from family and friends), project characteristics seem to be important: comprehensive, capital-intensive projects should increase the dependence of outside financing and therefore the overvaluation effect.

The risk-avoidance effect as well as the non-termination effect crucially depend on the difference between the values of the future growth opportunities and the liquidation values. If liquidation values are high, then the risk-avoidance effect should be rather low whereas the non-termination effect should be rather high. Growth opportunities act the opposite way. Thus, better growth opportunities increase the risk-avoidance effect and decrease the non-termination effect. We expect growth opportunities to be relatively more important for technology-intensive projects whereas the liquidation value crucially depends on the tangibility of assets. Therefore, human-capital intensive projects should be related to a rather low liquidation value compared to capital-intensive project. Additionally, rather specific investments in tangible assets should produce a lower liquidation value than more general investments. Furthermore, the importance of growth opportunities also depends on the industry approach. In industries with short technological cycles or with a strong first- 
mover advantage, for example, growth opportunities should be less important. Besides, both the RA as well as the NT effects also depend on the E's private control benefits $F$. In closely-held firms, the RA (NT) effect should be more (less) pronounced.

As concerns the commitment cost effect, it mainly depends on the behavior of the banking sector. We expect that a low market power of banks leads to a lower commitment cost effect because the banks are not able to include restrictive covenants due to competition. In addition, if we conjecture that a more developed banking sector has access to more sophisticated screening and monitoring technologies and thus has to rely less on ex ante restrictions, the development stage of the banking sector will also influence the commitment cost effect.

Finally, proposition 3 also shows that the choice of a specific financing sequence depends on the percentage of H-projects in the respective industry $(q)$. This is due to the fact that the NT effect decreases with an increase in $q$ while the RA effect increases. The percentage of $\mathrm{H}$ projects in an economy can be interpreted as a parameter about the quality and the perspectives of risky projects. Therefore, we conjecture that during boom periods or in highly growing economies, $q$ should be lower, i.e. the quality of risky projects should be higher. The same should be true for industries for which a specific country has comparative advantages.

Taking into account these different interpretations, we can state the following two hypotheses which relate the three financing decisions to project and firm characteristics as well as general conditions of the respective countries.

Hypothesis 1 We expect to observe different financing sequences depending on project and firm characteristics.

- Debt financing at both development stages as well as equity financing at the startup stage and debt financing at the expansion stage should be more probable than pure equity financing for firms that realize rather capital-intensive projects relying on non-specific investments in tangible assets or operating in an industry with a first-mover advantage.

- Equity financing at both development stages should be more probable than equity financing at the start-up stage and debt-financing at the expansion stage for closelyheld firms.

Hypothesis 2 We further expect to observe different financing sequences depending on the country in which the firm is located.

- In countries in which entrepreneurs heavily depend on outside financing, debt financing as well as equity financing at both development stages should be more probable than equity-debt financing.

- In countries in which entrepreneurs suffer from rather high stigmatization costs due to failure equity financing at both development stages should be more probable than equity-debt financing. 
- In countries in which the banking sector has a relatively high market power or is less developed, debt financing at both development stages should be less probable than pure equity financing.

- During boom periods, in highly growing economies or in industries where the specific country has a comparative advantage, start-up equity financing should become more probable than start-up debt financing.

It is also interesting to analyze the financing decisions of the expansion stage if the institutional conditions of a specific country impose financing constraints at the start-up stage. In section 7, we analyzed the impact of these constraints. Thereby, we have shown that if debt financing is not available for start-up companies, the financing decision at the expansion stage for risky projects depends on the relative size of the NT and OV effect (lemma 1) whereas if equity financing is not available for start-up companies, it depends on the relative size of the NT and the RA effect (lemma 2). In addition, we will also consider the results of section 7 about the impact of a lack of start-up financing options on firm dynamics, i.e. the project choice decisions between the risky and the safe projects as well as the value of the risky projects.

Combining the results of section 7 with the above described and operationalized determinants of the different effects and comparing them with hypotheses one and two allows us to state the following two hypotheses:

Hypothesis 3 If the institutional conditions of a specific country restrict the availability of financing alternatives at the start-up stage, we expect the following financing decisions depending on general characteristics:

- Given a lack of start-up debt financing, equity financing at the expansion stage should be more probable than debt financing in countries in which entrepreneurs heavily depend on outside financing, i.e. do not have sufficient means and do not have access to sufficient money from family or friends.

- Given a lack of start-up equity financing, equity financing at the expansion stage should be more probable than debt financing during boom periods, in highly growing economies or in industries where the specific country has a comparative advantage.

Hypothesis 4 We expect that the impact of a lack of start-up equity or start-up debt financing on firm dynamics mainly depends on the following factors:

- A lack of start-up equity financing is especially harmful for firm dynamics in countries with a high proportion of widely held firms or firms with a low dependence on external financing, in countries where the entrepreneurs suffer little from stigmatization due to failure or in countries with underdeveloped banks or little competition between banks.

- A lack of start-up debt financing, on the contrary, is especially harmful for firm dynamics of firms which realize rather capital-intensive projects relying on nonspecific investments in tangible assets or operating in an industry with a first-mover advantage combined with a high dependence on external financing. 


\section{Conclusion}

The objective of the present analysis is to investigate the financing and investment patterns over a firm's life cycle. Thereby, our objective was twofold: on the one hand, we wanted to bridge entrepreneurial finance and corporate finance, on the other hand, we aimed at analyzing the interaction of a firm's financing and investment decisions over its life cycle. By spelling out a dynamic model which rests on a few main mechanisms depicting the costs of alternative financing modes, we are able to investigate the determinants of alternative financing sequences which are actually in line with observed stylized patterns. In addition, we provide testable hypotheses of the determinants of financing and investment patterns. Thus, we establish a theoretical basis for the empirical analysis of a firm's financing pattern over its life time and across firms as well as countries.

Obviously, this is only a first step towards closing the research gap of the analysis of a firm's life cycle financing and investment decisions putting particular emphasis on potential path dependencies and interaction across periods and decisions. Our analysis abstracts from potentially important informational asymmetries across the firm's life cycle. Furthermore, by only considering external financing sources explicitly, we abstract from the role of internal financial resources, most notably retained earnings. These are definitively interesting starting points for further research. 


\section{References}

P. Aghion, S. Bond, A. Klemm, and I. Marinescu. Technology and Financial Structure: Are Innovative Firms Different? Journal of European Economic Association, 2:277-288, 2004 .

J. Almeida Brito and K. John. Leverage and Growth Opportunities: Risk-avoidance Induced by Risky Debt. Unpublished Working Paper, 2002.

R.W. Anderson and K.G. Nyborg. Financing and Corporate Growth under Repeated Moral Hazard. Unpublished Working Paper, 2001.

M.J. Barclay, C.W. Smith, and E. Morellec. On the Debt Capacity of Growth Options. Journal of Business, 79(1):37-59, 2006.

A.N. Berger and G.F. Udell. The Economics of Small Business Finance: The Roles of Private Equity and Debt Markets in the Financial Growth Cycle. Journal of Banking and Finance, 22:613-673, 1998.

C.M. Bhaird and B. Lucey. What Determines the Capital Structure of SMEs: Irish Evidence. Unpublished Working Paper, 2006.

M. Boyer, A. Jacques, and M. Moreaux. Equity Financing and Investment in Technological Flexibility. Unpublished Working Paper, 2005.

L. Bulan and Z. Yan. Tests of the Pecking Order Theory and the Firm life-cycle. Unpublished Working Paper, 2009.

S. Byoun. Financial Flexibility and Capital Structure Decisions. Unpublished Working Paper, 2008.

G. Cassar. The Financing of Business Start-ups. Journal of Business Venturing, 19: 261-283, 2004.

I. Chakraborty. Investment and Financing under Reverse Asset Substitution. Unpublished Working Paper, 2009.

F. Chittenden, H. Graham, and P. Hutchinson. Small Firm Growth, Access to Capital Markets and Financial Structure: Review of Issues and an Empirical Investigation. Small Business Review, 8:56-67, 1996.

G.L. Clementi and H.A. Hopenhayn. A Theory of Financing Constraints and Firm Dynamics. The Quarterly Journal of Economics, 121(1):229-265, 2006. 
R.A. Cole. What Do We Know about the Capital Structure of Privately Held Firms? Evidence from the Surveys of Small Business Finance. Unpublished Working Paper, 2008 .

V.A. Dang. Leverage, Debt maturity and Firm Investment: An Empirical Analysis. Unpublished Working Paper, 2008.

T. Dangl and J. Zechner. Debt Maturity and the Dynamics of Leverage. Unpublished Working Paper, 2006.

D.W. Diamond. Monitoring and Reputation: The Choice between Bank Loans and Directly Placed Debt. Journal of Political Economy, 106:709-737, 1991.

Z. Fluck. Capital Structure Decisions in Small and Large Firms: A Life-Cycle Theory of Financing. Unpublished Working Paper, 2000.

M. Z. Frank and K. Goyal. Testing the Pecking Order Theory of Capital Structure. Journal of Financial Economics, 67:217-248, 2003.

S. Grossman and O. Hart. Financial Structure and Management Incentives. In J. McCall, editor, The Economics of Information and Uncertainty. University of Chicago Press, 1982.

C.A. Hennessy and T.M. Whited. Debt Dynamics. Journal of Finance, 60(3):1129-1165, 2005.

L.F. Klapper, V. Sarria-Allende, and R. Zaidi. A Firm-Level Analysis of Small and Medium Sized Entreprise Financing in Poland. Unpublished Working Paper, 2006.

X. Liu. Managerial Incentives, Ownership Control and External Finance: A Theory of Capital Structure. Unpublished Working Paper, 2006.

D.C. Mauer and A.J. Triantis. Interaction of Corporate Financing and Investment Decisions: A Dynamic Framework. Journal of Finance, 46:1253-1277, 1994.

A.M. Robb and D.T. Robinson. The Capital Structure Decisions of New Firms. Unpublished Working Paper, 2009.

S. Sarkar. Expansion Financing and Capital Structure. Unpublished Working Paper, 2007.

F. Sogorb Mira. How SME Uniqueness Affects Capital Structure: Evidence from a 19941998 Spanish Data Panel. Unpublished Working Paper, 2002.

I.A. Strebulaev. Do Tests of Capital Structure Theory Mean What they Say? Journal of Finance, 62:1747-1787, 2006. 
J. Tirole. The Theory of Corporate Finance. Princeton University Press, Princeton and Oxford, 2006.

S. Titman and S. Tsyplakov. A Dynamic Model of Optimal Capital Structure. Unpublished Working Paper, 2006. 


\section{A Derivation of $\tilde{q}_{E}^{S B(T)}$}

With equity-debt financing, the E's project choice decision differs from the optimal choice based on the comparison of the E's expected total payoff from realizing the risky projects with his total payoff of the safe project. Therefore, it is useful to compare his expected total payoff from the risky projects with the safe project from an ex ante point of view, i.e. with fairly priced financing claims for both the risky projects as well as the safe project:

$$
\begin{aligned}
& \left(1-\alpha_{1}\right)\left\{q\left[\left(1-\tau_{H}\right)\left(H+G^{H}\right)+\tau_{H} L^{H}\right]+\right. \\
& \left.(1-q)\left[\left(1-\tau_{L}\right)\left(H+G^{L}\right)+\tau_{L} G_{B}^{L}-\right] I_{2}\right\}-q \tau_{H} F>\left(1-\alpha_{1}\right)\left[H+G^{S}-I_{2}\right]
\end{aligned}
$$

Note that we take further account of the initial equity stake $\alpha_{1}$ and the liquidation of the $\mathrm{H}$-project in the B-state induced by debt financing at the expansion stage. Solving for $\mathrm{q}$ yields the critical value for the percentage of H-projects in the economy for which the two options are equivalent:

$$
\tilde{q}_{E}^{S B(T)}=\frac{G^{L}-G^{S}-\tau_{L}\left(H+G^{L}-G_{B}^{L}\right)}{\left(1-\tau_{L}\right)\left(H+G^{L}\right)+\tau_{L} G_{B}^{L}-\left[\left(1-\tau_{H}\right)\left(H+G^{H}\right)+\tau_{H}\left(L^{H}-\frac{F}{\left(1-\alpha_{1}\right)}\right)\right]} .
$$

\section{B Proof of Lemma 1:}

In a first step, we compare the expected total payoff of the risky projects with equity-debt financing as well as pure equity financing. In a second step, based on this comparison, we will analyze the different cases of lemma 1.

The financing decision at the expansion stage induces specific continuation decisions at $t=5$ (see table 2) for the risky projects. If $\mathrm{E}$ chooses debt financing, the H-project will be discontinued while the L-project will be continued in the B-state. Taking into account the continuation decisions as well as the first stage equity claim, we can state the E's expected total profit from realizing the risky projects as

$$
\begin{aligned}
\left(1-\alpha_{1}\right)\left\{q\left[\left(1-\tau_{H}\right)\left(H+G^{H}\right)+\tau_{H} L^{H}\right]+(1-q)\left[\left(1-\tau_{L}\right)(H\right.\right. & \left.\left.+G^{L}\right)+\tau_{L} G_{B}^{L}\right] \\
& \left.-I_{2}\right\}+\left(1-q \tau_{H}\right) F
\end{aligned}
$$

If $\mathrm{E}$ chooses equity financing, neither of the projects will be liquidated in the B-state. The E's expected total profit from realizing the risky projects is given by:

$$
\left(1-\alpha_{1}\right)\left\{q\left[\left(1-\tau_{H}\right)\left(H+G^{H}\right)+\tau_{H} G_{B}^{H}\right]+(1-q)\left[\left(1-\tau_{L}\right)\left(H+G^{L}\right)+\tau_{L} G_{B}^{L}\right]-I_{2}\right\}+F
$$

Comparing equations 27 and 28 shows that the E's expected profit is larger with debt financing than with equity financing if

$$
q \tau_{H}\left[L^{H}-G_{B}^{H}-\frac{F}{\left(1-\alpha_{1}\right)}\right]>0
$$


Rearranging equation 29 yields

$$
\begin{aligned}
q \tau_{H}\left[L^{H}-G_{B}^{H}-F\right]-q \tau_{H}\left[\frac{F}{\left(1-\alpha_{1}\right)}-F\right] & >0 \\
N T-O V & >0
\end{aligned}
$$

Thus, if $N T>(<) O V$, the E's expected total profit from realizing the risky projects is higher (lower) with debt financing than with equity financing.

As concerns the project choice decision induced by the different financing sequences (after equity financing in the start-up phase), we have to take into account the two critical cut-off levels $\tilde{q}_{E, E}$ (see equation 13) and $\tilde{q}_{E}^{S B(T)}$ which we deduced in appendix A. This is due to the fact that $\mathrm{E}$ has an incentive to choose the risky projects only for $q \leq \tilde{q}_{E}^{S B(T)}$ and does not take $\tilde{q}_{E, D}$ (see equation 15) as critical cut-off level as he anticipates that he will ultimately bear the risk-shifting costs. Due to the risk-shifting problem, we know further that $\tilde{q}_{E}^{S B(T)}<\tilde{q}_{E, D}$.

The order of these three critical values for $q$ and thus the financing choice depend on the relative size of the NT, OV and RS(E) effects. In what follows, we will determine the order for each of the cases of lemma 1.

1. $O V \leq N T$ means

$$
\begin{aligned}
q \tau_{H}\left[\frac{F}{\left(1-\alpha_{1}\right)}-F\right] & \leq q \tau_{H}\left[L^{H}-G_{B}^{H}-F\right] \\
\tau_{H}\left[L^{H}-\frac{F}{\left(1-\alpha_{1}\right)}\right] & \geq \tau_{H} G_{B}^{H}
\end{aligned}
$$

This implies that the denominator of $\tilde{q}_{E, E}$ is larger than the denominator of $\tilde{q}_{E}^{S B(T)}$, and thus $\tilde{q}_{E, E} \leq \tilde{q}_{E}^{S B(T)}$. Thus, if $O V \leq N T, \tilde{q}_{E, E} \leq \tilde{q}_{E}^{S B(T)}<\tilde{q}_{E, D}$. For $O V \leq N T$, E always prefers debt financing to equity financing for the risky projects (see equation 29). Thus, equity financing is only chosen to prevent risk-shifting induced by debt financing and commit to the choice of the safe project. The combined results are depicted in the following figure:

\begin{tabular}{cccccc} 
Risky projects & Risky projects & $\tilde{q}_{E, E}^{S B(T)}$ & Safe project & $\tilde{q}_{E, D}$ & Safe project \\
\hline Debt financing & Debt financing & & $\begin{array}{l}\text { Equity financing } \\
\text { to prevent risk-shifting }\end{array}$ & Debt/equity financing
\end{tabular}

Figure 3: Case 1: $O V \leq N T$

2. $O V>N T$ implies that $\tilde{q}_{E, E}>\tilde{q}_{E}^{S B(T)}$. Though, in this case, the location of $\tilde{q}_{E, D}$ is ambiguous and depends on the relative size of the $\mathrm{RS}(\mathrm{E})$ effect. 
a) $N T \geq O V-R S(E)$ means that

$$
\begin{aligned}
q \tau_{H}\left[L^{H}-G_{B}^{H}-F\right] & \geq q \tau_{H}\left[\frac{F}{\left(1-\alpha_{1}\right)}-F\right]-q \tau_{H}\left[D_{2}-L^{H}\right] \\
& \text { or } \\
\tau_{H} G_{B}^{H} & \leq \tau_{H}\left[D_{2}-\frac{F}{\left(1-\alpha_{1}\right)}\right]
\end{aligned}
$$

This implies that the denominator of $\tilde{q}_{E, E}$ is larger than the denominator of $\tilde{q}_{E, D}$, and thus $\tilde{q}_{E, E}<\tilde{q}_{E, D}$. Thus, in this case, $\tilde{q}_{E}^{S B(T)}<\tilde{q}_{E, E}<\tilde{q}_{E, D}$.

b) Consequently, $\tilde{q}_{E, D}<\tilde{q}_{E, E}$ if $N T<O V-R S(E)$ and thus, $\tilde{q}_{E}^{S B(T)}<\tilde{q}_{E, D} \leq$ $\tilde{q}_{E, E}$.

For $O V>N T$, E always prefers equity financing to debt financing for the risky projects (see equation 29). In addition, equity financing may be chosen to prevent risk-shifting. The combined results are depicted in the following figure:

\begin{tabular}{lllll} 
& \multicolumn{2}{c}{$\tilde{q}_{E, D}$ moves if $R S(E)$ increases } & Safe project \\
Risky projects $\tilde{q}_{E}^{S B(T)}$ & Risky projects & $\tilde{q}_{E, E}$ & Safe project & $\tilde{q}_{E, D}$ \\
\hline & Equity financing & Equity financing & Debt/equity financing \\
to prevent risk-shifting
\end{tabular}

Figure 4: Case 2: $O V>N T$

\section{Derivation of $\hat{q}(D)$}

In what follows, we will compare the total expected payoff of the risky projects with pure debt financing and with debt-equity financing. If $\mathrm{E}$ chooses debt financing, both the $\mathrm{H}-$ project and the L-project will be discontinued in the B-state while with equity financing both projects are continued. Moreover, we know that first-stage debt financing is riskless. Therefore, the E's expected total profit from realizing the risky projects with pure debt financing is given by:

$$
\begin{aligned}
q\left[\left(1-\tau_{H}\right)\left(H+G^{H}\right)+\tau_{H} L^{H}\right]+(1-q)\left[\left(1-\tau_{L}\right)\left(H+G^{L}\right)+\tau_{L} L^{L}\right] & \\
& -I_{2}-I_{1}+\left(1-q \tau_{H}-(1-q) \tau_{L}\right) F
\end{aligned}
$$

while his expected total profit with debt-equity financing is given by:

(31) $q\left[\left(1-\tau_{H}\right)\left(H+G^{H}\right)+\tau_{H} G_{B}^{H}\right]+(1-q)\left[\left(1-\tau_{L}\right)\left(H+G^{L}\right)+\tau_{L} G_{B}^{L}(D)\right]-I_{2}-I_{1}+F$. 
Comparing equations 30 and 31 shows that the E's expected profit of the risky projects is larger with debt financing than with equity financing if

$$
q \tau_{H}\left[L^{H}-G_{B}^{H}-F\right]>(1-q) \tau_{L}\left[G_{B}^{L}(D)+F-L^{L}\right] .
$$

Note that the first expression just corresponds to the non-termination effect (NT) while the second expression corresponds to the risk-avoidance effect (RA). Thus, if $N T>R A$ for a given q, the E's expected total profit from realizing the risky projects is higher with debt financing than with equity financing. However, as can be seen, both the non-termination as well as the risk-avoidance effect, depend on the value of q, i.e. the percentage of H-projects in the economy. But whereas the non-termination effect rises in q with $N T \in\left[0, \tau_{H}\left(L^{H}-\right.\right.$ $\left.\left.G_{B}^{H}-F\right)\right]$, the risk-avoidance effect decreases in q with $R A \in\left[0, \tau_{L}\left(G_{B}^{L}(D)+F-L^{L}\right)\right]$. Thus, there must exist a critical $\hat{q}(D)$ for which both effects are equal given by

$$
\hat{q}(D)=\frac{\tau_{L}\left(G_{B}^{L}(D)+F-L^{L}\right)}{\tau_{L}\left(G_{B}^{L}(D)+F-L^{L}\right)+\tau_{H}\left(L^{H}-G_{B}^{H}-F\right)}
$$

This implies that if $q<\hat{q}(D)$, the expected loss from the continuation of the H-project (non-termination effect) is smaller than the expected loss from the liquidation of the Lproject (risk-avoidance effect) and therefore, the E's expected total payoff of the risky projects is higher under equity financing. On the other hand, for $q>\hat{q}(D)$, the riskavoidance effect is smaller than the non-termination effect and thus the E's expected total payoff of the risky projects is higher under debt financing.

\section{Derivation of $\tilde{q}_{D}^{S B(T, T)}$}

With pure debt financing, the E's project choice decision differs from the optimal choice based on the comparison of the E's expected total payoff from realizing the risky projects with his total payoff of the safe project. Therefore, it is useful to compare his expected total payoff from the risky projects anticipating the liquidation of both projects in the B-state with the safe project from an ex ante point of view, i.e. with fairly priced financing claims for both the risky projects as well as the safe project:

$$
\begin{aligned}
q\left[\left(1-\tau_{H}\right)\left(H+G^{H}\right)+\tau_{H} L^{H}\right] & +(1-q)\left[\left(1-\tau_{L}\right)\left(H+G^{L}\right)+\tau_{L} L^{L}\right]-I_{2}-I_{1} \\
& +\left(1-q \tau_{H}-(1-q) \tau_{L}\right) F>H+G^{S}-I_{1}-I_{2}+F
\end{aligned}
$$

Solving for q yields the critical value for the percentage of H-projects in the economy for which the two options are equivalent:

$$
\tilde{q}_{D}^{S B(T, T)}=\frac{G^{L}-G^{S}-\tau_{L}\left[H+G^{L}-L^{L}-F\right]}{\left(1-\tau_{L}\right)\left(H+G^{L}\right)+\tau_{L}\left(L^{L}-F\right)-\left(1-\tau_{H}\right)\left(H+G^{H}\right)-\tau_{H}\left(L^{H}-F\right)} .
$$




\section{E Proof of Lemma 2:}

In order to be able to analyze the E's financing choice, we have to take into account the two critical cut-off levels $\tilde{q}_{D, E}$ (see equation 11) and $\tilde{q}_{D, D}$ (see equation 9 ) which determine the project choice decision. Though, E has again an incentive to choose the risky project too often with pure debt financing $\left(\tilde{q}_{D}^{S B(T, T)}<\tilde{q}_{D, D}\right.$ see appendix D). With debt-equity financing, on the contrary, the risk-shifting effect does not manifest because first stage debt is riskless. Analogously to the case of lemma 1, E anticipates that he has to bear ultimately the costs of risk-shifting and thus he would prefer to choose the risky projects with pure debt financing only for $q \leq \tilde{q}_{D}^{S B(T, T)}$ (see appendix D). This implies that the total expected payoff for $\mathrm{E}$ is higher with the risky projects than with the safe project for $q \leq \max \left[\tilde{q}_{D}^{S B(T, T)} ; \tilde{q}_{D, E}\right]$.

The order of these three critical values for q as well as the critical $\hat{q}(D)$ which compares the E's total expected payoff with the risky projects under both financing alternatives (see appendix C) finally determines the financing choice and depends on the relative size of the NT, RA and RS(D) effects. In what follows, we will determine the order for each of the cases of lemma 2 .

1. $N T \geq R A$ for $\tilde{q}_{D}^{S B(T, T)}$ means

$$
\tilde{q}_{D}^{S B(T, T)} \tau_{H}\left[L^{H}-G_{B}^{H}-F\right] \geq\left(1-\tilde{q}_{D}^{S B(T, T)}\right) \tau_{L}\left[G_{B}^{L}(D)+F-L^{L}\right] .
$$

Thus for $q=\tilde{q}_{D}^{S B(T, T)}$, equation 32 holds: the E's total expected payoff of the risky projects is higher with debt financing $\left(E\left(R_{D}\right)\right)$ than with equity financing $\left(E\left(R_{E}\right)\right)$. As for $q=\tilde{q}_{D}^{S B(T, T)}$, the E's total expected payoff with debt financing just corresponds to the E's total payoff with the safe project $\left(E\left(R_{D}\right)=S\right), E\left(R_{E}\right)<S$. As the total payoff of the risky projects decreases in q, this implies that $\tilde{q}_{D}^{S B(T, T)}>\tilde{q}_{D, E}$. In addition, as NT decreases and RA increases with a decrease in q and for $q=0$, $N T<R A$, the critical $\hat{q}(D)$, which indicates the percentage of H-projects in the economy for which both effects are the same, must be smaller than $\tilde{q}_{D, E}$. Thus, $\hat{q}(D)<\tilde{q}_{D, E}<\tilde{q}_{D}^{S B(T, T)}$. The following figure sums up these results:

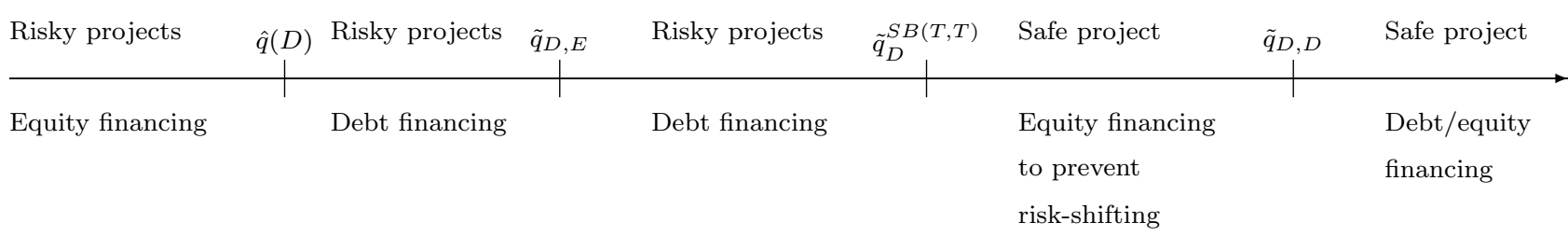

Figure 5: Case 1: $N T \geq R A$ for $\tilde{q}_{D}^{S B(T, T)}$ 
2. Analogously to the first case, we know that if $R A>N T$ for $\tilde{q}_{D}^{S B(T, T)}$, equation 32 does not hold anymore: the E's total expected payoff of the risky projects is higher with equity financing than with debt financing: $\left(E\left(R_{E}\right)>E\left(R_{D}\right)\right)$. As for $q=\tilde{q}_{D}^{S B(T, T)}, E\left(R_{D}\right)=S, E\left(R_{E}\right)>S$, and thus- as the total payoff of the risky projects decreases in $\mathrm{q}-\tilde{q}_{D}^{S B(T, T)}<\tilde{q}_{D, E}$. In addition as NT increases and RA decreases with an increase in q and for $q=1, N T>R A$, the critical $\hat{q}(D)$ (the percentage of $\mathrm{H}$-projects in the economy for which both effects are the same) must be larger than $\tilde{q}_{D, E}$. Thus, $\tilde{q}_{D}^{S B(T, T)}<\tilde{q}_{D, E}<\hat{q}(D)$. However, in this case, the location of $\tilde{q}_{D, D}$ is ambiguous and depends on the relative size of the $\mathrm{RS}(\mathrm{D})$ effect.

a) $N T \geq R A-R S(D)$ for $\tilde{q}_{D, E}$ means that

$$
\begin{aligned}
\left(1-\tilde{q}_{D, E}\right) \tau_{L}\left(G_{B}^{L}(D)+F-L^{L}\right)-\left[\tilde{q}_{D, E} \tau_{H}\left(D_{1}+D_{2}-L^{H}\right)\right. \\
\left.\quad+\left(1-\tilde{q}_{D, E}\right) \tau_{L}\left(D_{1}+D_{2}-L^{L}\right)\right] \leq \tilde{q}_{D, E} \tau_{H}\left(L^{H}-G_{B}^{H}-F\right)
\end{aligned}
$$

Rearranging yields

$$
\left(1-\tilde{q}_{D, E}\right) \tau_{L}\left[G_{B}^{L}(D)+F-D_{1}-D_{2}\right] \leq \tilde{q}_{D, E} \tau_{H}\left[D_{1}+D_{2}-G_{B}^{H}-F\right]
$$

or

$$
\begin{aligned}
& \tilde{q}_{D, E}\left[\left(1-\tau_{H}\right)\left(H+G^{H}\right)+\tau_{H} G_{B}^{H}\right]+\left(1-\tilde{q}_{D, E}\right)\left[\left(1-\tau_{L}\right)\left(H+G^{L}\right)+\tau_{L} G_{B}^{L}(D)\right] \\
\leq & \tilde{q}_{D, E}\left[\left(1-\tau_{H}\right)\left(H+G^{H}+F-D_{1}-D_{2}\right)\right]+\left(1-\tilde{q}_{D, E}\right)\left[\left(1-\tau_{L}\right)\left(H+G^{L}+F-D_{1}-D_{2}\right)\right]
\end{aligned}
$$

This last equation shows that if $N T \geq R A-R S(D)$ for $\tilde{q}_{D, E}$, the E's expected

\begin{tabular}{|c|c|c|c|c|c|}
\hline Risky projects $\tilde{q}_{D}^{S B(T, T)}$ & Risky projects & $\tilde{q}_{D, E}$ & Safe project & $\tilde{q}_{D, D}$ & Safe project \\
\hline Equity financing & Equity financing & & $\begin{array}{l}\text { Equity finan } \\
\text { to prevent ri }\end{array}$ & & Debt/equity financing \\
\hline
\end{tabular}
total ex-post payoff is higher with debt than with equity financing for $\tilde{q}_{D, E}$, and therefore, $\tilde{q}_{D, E}<\tilde{q}_{D, D}$.

b) Consequently, if $N T<R A-R S(D)$ for $\tilde{q}_{D, E}$, then $\tilde{q}_{D, E}>\tilde{q}_{D, D}$.

The following figure sums up these results:

Figure 6: Case 2: $N T<R A$ for $\tilde{q}_{D}^{S B(T, T)}$ 


\section{F Proof of Proposition 3:}

E will choose the financing form at the start-up stage which maximizes the project's total payoff anticipating the financing choice at the expansion stage, the project choice as well as the continuation decisions. We know that equity-debt financing leads to the optimal continuation decisions at $t=5$. Therefore, if $\mathrm{E}$ can commit to choose debt financing at the expansion stage, he will choose equity financing at the start-up stage to maximize the total expected payoff of the risky projects. We know from lemma 1 case 1 that this will always be the case if $O V \leq N T$ but not for $O V>N T$. Thus, we will distinguish these two main cases.

Case 1: $O V \leq N T$ :

If $\mathrm{E}$ can commit to choose debt financing at the expansion stage for the risky projects, he will choose equity financing at the start-up stage for $q \leq \tilde{q}_{E}^{S B(T)}$ to maximize the total expected payoff of the risky projects. However, even if first-best continuation decisions can be achieved, the project choice decision is biased due to the overvaluation effect. We know that the risky projects are chosen only if

$$
\begin{aligned}
& q\left[\left(1-\tau_{H}\right)\left(H+G^{H}\right)+\tau_{H} L^{H}\right]+(1-q)\left[\left(1-\tau_{L}\right)\left(H+G^{L}\right)+\tau_{L} G_{B}^{L}\right]- q \tau_{H} \frac{F}{\left(1-\alpha_{1}\right)} \\
& \geq\left[H+G^{S}\right]
\end{aligned}
$$

In this case, debt financing at the start-up stage may prevent the evasion to the safe project caused by the overvaluation effect. After debt financing at the start-up stage, we have to distinguish two cases.

First, according to lemma 2, case 1 , for $N T \geq R A$ for $q=\tilde{q}_{D}^{S B(T, T)}$, E will choose the risky projects if

$$
\begin{aligned}
q\left[\left(1-\tau_{H}\right)\left(H+G^{H}\right)+\tau_{H} L^{H}\right]+(1-q)\left[\left(1-\tau_{L}\right)\right. & \left.\left(H+G^{L}\right)+\tau_{L} L^{L}\right] \\
& -q \tau_{H} F-(1-q) \tau_{L} F \geq H+G^{S}
\end{aligned}
$$

Note that $\mathrm{E}$ takes account of the choice of debt financing at the expansion stage and therefore the liquidation of both types of risky projects in the B-state. Comparing equations 37 and 38 shows that the expected payoff of the risky projects at the expansion stage is higher after start-up debt financing than after start-up equity financing if

$$
\begin{aligned}
-(1-q) \tau_{L}\left[G_{B}^{L}+F-L^{L}\right]+q \tau_{H}\left[\frac{F}{\left(1-\alpha_{1}\right)}-F\right] & >0 \\
(1-q) \tau_{L}\left[G_{B}^{L}(D)+F-L^{L}\right]+(1-q) \tau_{L}\left[G_{B}^{L}-G_{B}^{L}(D)\right] & <q \tau_{H}\left[\frac{F}{\left(1-\alpha_{1}\right)}-F\right]
\end{aligned}
$$

This implies that if the $O V \geq R A+C C$ for $q=\tilde{q}_{D}^{S B(T, T)}$, then the risky projects are implemented more frequently with debt financing at the start-up stage. Consequently, debt 
financing will be chosen for $\tilde{q}_{E}^{S B(T)}<q \leq \tilde{q}_{D}^{S B(T, T)}$ in order to avoid the evasion to the safe project caused by the overvaluation effect (see proposition 3, case 1a). Otherwise, if $O V<$ $R A+C C$ for $q=\tilde{q}_{D}^{S B(T, T)}$, then the risky projects are implemented less frequently with debt financing at the start-up stage and thus $\mathrm{E}$ is indifferent between the financing forms for $q>\tilde{q}_{E}^{S B(T)}$ anticipating that the safe project will always be chosen (see proposition 3, case $1 b)$.

Second, according to lemma 2, case 2 , for $N T<R A$ for $\tilde{q}_{D}^{S B(T, T)}$, E will choose the risky projects if

$$
q\left[\left(1-\tau_{H}\right)\left(H+G^{H}\right)+\tau_{H} G_{B}^{H}\right]+(1-q)\left[\left(1-\tau_{L}\right)\left(H+G^{L}\right)+\tau_{L}\left(G_{B}^{L}(D)\right)\right] \geq H+G^{S}
$$

Comparing equation 37 and 39 shows that the risky projects are implemented more frequently after start-up equity financing than after start-up debt financing. Thus, $\mathrm{E}$ is indifferent between the financing forms anticipating that the safe project will always be chosen for $q>\tilde{q}_{E}^{S B(T)}$ (see proposition 3, case $1 \mathrm{~b}$ ).

Case 2: $O V>N T$ :

In this case, E cannot commit to choose debt financing at the expansion stage and thus the first-best efficient continuation decisions can never be achieved. Indeed, equity financing at the start-up stage will imply equity financing at the expansion stage and thus an inefficient continuation of the H-project in the B-state. Then, however, equity financing at the start-up stage may no longer produce a higher expected total payoff for E with the risky projects than debt financing. In order to be able to compare start-up equity and debt financing, we have to distinguish two cases as to debt financing.

First, according to lemma 2 , case 1 , for $N T \geq R A$ for $\tilde{q}_{D}^{S B(T, T)}$, E will choose debt financing to finance the risky projects for $\hat{q}(D)<q \leq \tilde{q}_{D}^{S B(T, T)}$. Then, we have to compare the E's expected total payoff after pure equity financing given by

$$
q\left[\left(1-\tau_{H}\right)\left(H+G^{H}\right)\right]+\tau_{H} G_{B}^{H}+(1-q)\left[\left(1-\tau_{L}\right)\left(H+G^{L}\right)+\tau_{L} G_{B}^{L}\right]+F-I_{1}-I_{2}
$$

with his expected total payoff after pure debt financing given by

$$
q\left[\left(1-\tau_{H}\right)\left(H+G^{H}+F\right)+\tau_{H} L^{H}\right]+(1-q)\left[\left(1-\tau_{L}\right)\left(H+G^{L}+F\right)+\tau_{L} L^{L}\right]-I_{1}-I_{2} .
$$

Comparing equations 40 and 41 shows that his expected total payoff is higher with debt financing than with equity financing if

$$
q \tau_{H}\left[L^{H}-F-G_{B}^{H}\right]-(1-q) \tau_{L}\left[G_{B}^{L}+F-L^{L}\right]>0
$$

Rearranging yields

$$
q \tau_{H}\left[L^{H}-F-G_{B}^{H}\right]>(1-q) \tau_{L}\left[G_{B}^{L}(D)+F-L^{L}\right]+(1-q) \tau_{L}\left[G_{B}^{L}-G_{B}^{L}(D)\right]
$$


This means that debt financing is preferred if $N T>R A+C C$ for a given q. If $N T>$ $R A+C C$ for $\tilde{q}_{D}^{S B(T, T)}$, this implies that $N T>R A+C C$ for all $q>\tilde{q}_{D}^{S B(T, T)}$. However, for smaller values of $\mathrm{q}$ the relation inverts. Thus, there exist a critical value $\hat{q}$ for which $N T=R A+C C$ which is given by

$$
\hat{q}=\frac{\tau_{L}\left(G_{B}^{L}+F-L^{L}\right)}{\tau_{L}\left(G_{B}^{L}+F-L^{L}\right)+\tau_{H}\left(L^{H}-G_{B}^{H}-F\right)}
$$

Note that as $G_{B}^{L}>G_{B}^{L}(D), \hat{q}>\hat{q}(D)$. Thus, if $N T \geq R A+C C$ for $\tilde{q}_{D}^{S B(T, T)}$, E will choose start-up debt financing for $\hat{q}<q \leq \tilde{q}_{D}^{S B(T, T)}$. For $q \leq \hat{q}$ E will still choose start-up equity financing as then again $N T<R A+C C$ (see proposition 3 case $2 \mathrm{a}$ ). On the other hand, if $N T<R A+C C$ for $\tilde{q}_{D, E}$, E will always choose start-up equity financing to finance the risky projects for $q \leq \tilde{q}_{E, E}$ (see proposition 3 case $2 \mathrm{~b}$ ).

Second, according to lemma 2, case 2 , for $N T<R A$ for $\tilde{q}_{D}^{S B(T, T)}$, E will choose equity financing to finance the risky projects. In these cases, however, start-up debt financing induces the same continuation decisions as start-up equity financing but $\mathrm{E}$ has to assume additionally the commitment costs of debt. Thus, in this case, E will always prefer startup equity financing to finance the risky projects, i.e. for $q \leq \tilde{q}_{E, E}$ (see proposition 3 case $2 \mathrm{~b})$. 